\title{
The Influence of Stadia and the Built Environment on the Spatial Distribution of Crime
}

\author{
Justin Kurland \& Shane D Johnson
}

\begin{abstract}
Objectives: The aim of this study was to explore the influence of "micro-" (e.g., pubs and fast-food restaurants) and "super-facilities" on area level counts of crime. Soccer stadia were selected as an example of a super-facility as their episodic use provides conditions not unlike a natural experiment. Of particular interest was whether the presence of such facilities, and their influence on the flow of people through neighborhoods on match days affects crime. Consideration was also given to how the social composition of a neighborhood might influence crime.

Methods: Crime, street network, and points of interest data were obtained for the areas around five UK soccer stadia. Counts of crime were computed for small areal units and the spatial distribution of crime examined for match and non-match days. Variables derived from graph theory were generated to estimate how micro-facilities might influence the movement flows of people on match days. Spatial econometric analyses were used to test hypotheses.

Results: Mixed support was found for the influence of neighborhood social composition on crime for both match and non-match days. Considering the influence of facilities, a selective pattern emerged with crime being elevated in those neighborhoods closest to stadia on match but not non-match days. Micro-facilities too were found to influence crime levels. Particularly clear was the finding that the influence of pubs and fast-food restaurants on estimated movement flows to and from stadia on match (but not non-match) days was associated with area level crime.

Conclusions: Our findings provide further support for ecological theories of crime and how factors that influence the likely convergence of people in urban spaces affect levels of crime.
\end{abstract}




\section{INTRODUCTION}

A growing literature demonstrates that crime is spatially concentrated (Weisburd 2015). Theories intended to explain this regularity consider both how the social fabric of a community might affect levels of crime (e.g., Shaw and McKay 1942), and how people's routine activities (Cohen and Felson 1979) — and the associated flows of people through specific places at specific times - might create the necessary conditions for crime to occur. In this paper, we consider how particular types of facilities and the street network that connects them might affect the ecology of an area and in doing so levels of crime. More specifically, the influence of small (or "micro-level") facilities that might feature in many people's everyday activities, such as pubs and fast-food restaurants are considered. We also consider the role of what we refer to as "super-facilities" whose use may be episodic but can both influence the movement of people to and around them, and people's use of other facilities in the vicinity. In this paper we focus on soccer stadia as an example of one kind of "superfacility."

To this end, the spatial distributions of crime around five UK soccer stadia (Aston Villa, Leeds United, Sheffield United, Sheffield Wednesday and Wolverhampton Wanderers) on days when matches are played — and hence these facilities are likely to influence the movement of people to and around them — and those on which they are not are examined. We employ a multivariate spatial econometric approach to compare the social and physical characteristics of those neighborhoods where offenses are (and are not) committed on match and non-match days to estimate the contribution of a range of environmental characteristics on area levels of crime. The research complements recent efforts that have sought to examine 
the criminogenic effect (if any) of casinos (see Johnson and Ratcliffe 2014) and other "risky facilities" such as bars (e.g., Bowers 2014) on crime in the surrounding area.

This article is organized as follows: First, we discuss key ecological theories of crime pattern formation and provide a conceptual account of how risky facilities and "superfacilities" might affect levels of crime. We then discuss why soccer stadia present a unique opportunity to explore differences in the spatial distribution of crime and disorder under contrasting ecological conditions, before briefly discussing theories of social disorganization as an alternative (or complementary) explanation for spatial patterns of crime. A description of the analytical strategy adopted is then presented, followed by an explanation as to why such an approach is appropriate. After presenting our findings, their implications for criminological theory, policy and practice are discussed.

\subsection{ROUTINE ACTIVITY AND CRIME PATTERN THEORY}

Numerous theories of urban crime have been influenced by ideas from ecology. Among these is Cohen and Felson's (1979) routine activity theory. This theory considers how the ecological conditions created by people's everyday movements and changes in them influence the likelihood of crime. In particular, it states that the necessary conditions for crime to occur are the convergence in space and time of a motivated offender and suitable target, absent an intimate handler and capable guardian or place manager (Felson 1986; Eck 1994). From this perspective, peoples' routine activities shape the likelihood of such convergences and hence the opportunities for crime to occur in a match day context. 
According to crime pattern theory (e.g., Brantingham and Brantingham 1993), as a consequence of their routine movement patterns, offenders (like everyone else) develop activity spaces that influence the opportunities for crime they become aware of and are able to exploit (at the time or a later one). The structure of these activity spaces can be described in terms of: (1) nodes, those places where activity occurs (e.g., places of work or recreation); (2) paths, those routes commonly used to move from one node to another; and, (3) edges, the boundaries that separate the places people frequent and those that they do not. Crime pattern theory suggests that it is at the locations a given offender's activity space intersects with suitable opportunities for crime that offenses will most likely occur. Moreover, that crime hotspots will form where offender activity spaces collectively overlap with opportunities for crime that they are motivated to, and capable of exploiting.

Put differently, as a consequence of the aggregation of people's activity patterns, the necessary conditions for crime are likely to be higher in some places more than others. Observing this, Brantingham and Brantingham (1995) identified two types of "crime hotspots". The first are "crime generators", which are locations (or facilities) that attract a large number of people to them for legitimate purposes. Crime generators might include transit stations, shopping areas or soccer stadia that large numbers of people visit, but they can include smaller facilities too. Offenders will be amongst those who travel to or through these types of areas (or facilities), and while they may not visit them with the intention of committing crime, they can take advantage of the serendipitous opportunities they encounter (Brantingham and Brantingham 1995). In contrast, a "crime attractor" is a hotspot location (or facility) to which motivated offenders travel with the aim of offending because of known crime opportunities. Crime attractors include locations that are known to have drug markets or red-light districts where targets are likely to be found and where there will be few capable 
guardians who are likely to intervene. The two types of hotspot are thus generated by different mechanisms that influence the mix and volume of people that travel to or through them.

The location and operation of everyday facilities such as bars and fast-food restaurants can influence the activity patterns of many people, including offenders, which can in turn affect where crimes occur. Such facilities may generate crime as a byproduct of their influence on people's movement patterns (crime generators) or attract offenders to locations where good criminal opportunities are known to exist (crime attractors). As will be discussed next, facilities may not only influence criminal opportunity within them, but in the surrounding environment. In particular, the flow of people (including offenders) to and from a particular facility can affect the mix (and volume) of people and hence the likelihood of crime occurrence in the areas near to or on the way to them. A considerable body of research demonstrates that the placement of activity nodes is associated with crime pattern formation (for reviews, see Groff and Lockwood 2014; see also Bernasco and Block 2011). For example, studies have shown that the likelihood of crime is greater at locations near to bars or liquor stores (e.g., Bowers 2014; Jennings et al. 2014; Grubesic et al. 2013; Ratcliffe 2012), schools (e.g., LaGrange and Silverman 1999; Roman 2005), and transit stations (Roncek and Lobosco 1983; Bernasco and Block 2011; Haberman and Ratcliffe 2015).

In addition to crime clustering around a variety of activity nodes, research also suggests that it is concentrated within particular facilities. For example, in their review of crimes within facilities, Wilcox and Eck (2011) conclude that a small fraction of what they refer to as "risky facilities" — be they bars, schools, banks, etc.—account for a large proportion of all offenses. What this means is that particular types of facilities may not necessarily be criminogenic in and of themselves, but that some specific facilities are. One reason for this, as discussed by Wilcox and Eck (2011: p. 476) is that it is “... the busy nature of facilities in 
general and the busy context in which facilities are often situated, rather than the facility type itself, that generates crime". That is, what drives these patterns may be the influence that such facilities (and those nearby) have on the movement of people to and around them (Bowers 2014).

Different types of risky facilities vary in terms of how many people's activity patterns they might influence. "Micro-facilities" such as bars may be localized in their extent, influencing the activity patterns of a limited number of people. Indeed, research by Ratcliffe (2012) in Philadelphia suggests that bars increase the likelihood of violence at locations up to $26 \mathrm{~m}$ (85 feet) away, and that their influence dissipates rapidly (see also Groff and Lockwood 2014). However, large-scale or "super-facilities" as we will refer to them hereafter, such as soccer stadia and transit nodes, can influence the activity of a substantial number of people simultaneously across a much wider geographical area (Breetzke and Cohn 2013; Kurland, Johnson, and Tilley 2014). Moreover, in addition to the direct influence such facilities might have on people's movement to and from them, "super-facilities" may have more indirect effects by encouraging the movement of people to and from facilities at nearby locations. To elaborate, consider that prior to attending a soccer match, supporters may and typically do ${ }^{1}$ (see "National Fan Survey" 2005, 2006, 2007 and 2008) visit other activity nodes such as bars and fast-food restaurants that they otherwise might not. This can increase the number of people (including potential offenders) visiting them on match days. Moreover, given that soccer matches have a specific start and end time, it is not only the case that more people will visit them, but (unlike many other days) they may do so at or around the same time, thereby

\footnotetext{
${ }^{1}$ For example, fan surveys for the 2005/06 through the 2009/10 seasons of professional soccer in the UK indicate that approximately one-quarter to one-third of all fans used public transport to attend matches during this period. Moreover, roughly one-half of all supporters go to a pub, and one-quarter of all supporters eat outside the ground and get fast food prior to match kickoffs.
} 
changing the criminal opportunity structure at particular places and times, increasing the potential for provocations (Wortley 1997) and hence crime.

In addition to influencing the use of nearby activity nodes, "super-facilities" will also increase the flow (or movement potential) of people between the two on those days that the latter are used. In so doing, this is likely to change the ecology of the areas in between them (on match days) at particular times of the day, thereby creating conditions conducive to, and potentially generating crime in, around and between these locales.

If the activity patterns of supporters on match days do affect the likelihood of crime, then it follows that the configuration of the environmental backcloth will affect where crimes are most likely to occur on such days. In particular, the configuration of the street network in combination with the constellation of risky facilities across this backcloth shapes how people, including offenders, move in space and consequently affects the opportunities for crime offenders become aware of (Beavon et al. 1994; Johnson and Bowers 2010) or encounter. Obviously, offenders could seek opportunities outside of their activity/awareness spaces. However, the principle of least effort (Zipf 1949) and journey-to-crime literature (for a review, see Townsley and Sidebottom 2010) suggest that most offenders commit crime in close proximity to their activity nodes, such as the home or other activity nodes (Roncek and Bell 1981; Roncek and Maier 1991; Rengert and Wasilchick 2000; Bernasco 2013; Frith et al. 2017). Thus, in accordance with crime pattern theory, on match days (when a stadium is used), we hypothesize that crime should be more likely to occur along those paths (and the nodes through which they pass) that make up offender and target activity spaces and that connect a "super-facility" to micro-facilities (e.g., pubs) that supporters are likely to visit on those days. 
As Taylor (2015) points out, one problem with existing studies concerned with the impact of risky facilities and land use more generally on crime is that studies are cross-sectional. That is, they examine the correlation between the presence or absence of facilities for some fixed interval of time. Put differently, the facilities are either there or not and their influence is assumed (analytically at least) to be constant over time. As such, causal inference is limited since there is no way of establishing that cause precedes effect.

In the case of soccer matches, these do not take place every day, and hence the use of stadia - and the influence they have on the ecology of an area - is episodic. Thus, studying spatial patterns of crime around such "super-facilities" presents an opportunity-akin to a natural experiment - to observe how changes to the potential movement of people to and around them (on match days) affects spatial patterns of crime. This can be contrasted to days when the stadia are unused. On such days, the nodes people visit and the paths they take should largely be unaffected by the location of the stadium (unless they are co-located with other heavily used facilities). In fact, very different patterns of movement may be expected because other facilities that people are more likely to visit on such days may be located elsewhere. For instance, the primary shopping or entertainment district (or high street) in most cities is generally located several kilometers from a soccer stadium (in the UK at least). Consequently, those seeking entertainment on days when matches are not played are less likely to travel to locations near stadia or to travel those routes that would connect their nonmatch day activity nodes to the stadium.

\subsection{CRIME IN AND AROUND "SUPER-FACILITIES"}

While there exist a number of different types of "super-facility", in this paper we focus on sports stadia as one example. As noted above, the number of empirical studies that have 
examined the impact of such "super-facilities" on crime remains limited. However, those have consistently demonstrated statistically significant increases in the count, as well as differences in the overall distribution of crime, on days when sports stadia are used compared to when they are not. In this section, we briefly review these studies, starting with those for which analyses were conducted for the largest areal units. In their study, Campaniello (2011) used Italian crime data, collected at the provincial-level in Italy, for the 1990 Soccer World Cup. They use a regression model with a fixed effect estimator (to capture province-level heterogeneity) and found both a significant increase in property crimes (e.g., pick-pocketing, shoplifting, and burglary) and violent crime. Munyo and Rossi (2013) adopted a similar approach to study levels of crime at the city-level in Montevideo, Uruguay on days when the local soccer team played. They found a significant increase in (city-wide) robbery when the local soccer team (Penarol) experienced a loss.

$\mathrm{Yu}$ et al. (2016) examined the relationship between the timing of National Basketball Association and National Collegiate Athletic Association Men's Basketball games taking place at the FedEx Forum arena and hourly robbery counts across the city of Memphis, TN. Using a multivariate regression that controlled for variables potentially associated with crime, such as the lunar cycle and temperature, they found a significant increase in the volume of individual robberies when home games occurred. However, on days when televised away games took place — and hence fans were not travelling to the arena — there were no differences in the level of crime. More recently, Kurland (2019) examined hourly robbery rates across the city of Newark, NJ for nine different types of events — including professional and collegiate basketball, ice hockey, boxing, as well as concerts and "Disney on Ice" shows that took place at the Prudential (sports and entertainment) Center over the period 2007-2015. Controlling for light conditions, temperature, and other factors, Kurland (2019) found that for 
the period two hours immediately before events, the hour during events, and for the threehour period afterwards, there were increases (of $20 \%$ or more) in the number of robberies for National Hockey League games, music concerts, and Disney on Ice shows.

Other studies have examined changes to the spatial pattern of crime around stadia in more detail. For example, Breetzke and Cohn (2013) compared how the count of crime differed within buffer zones (half a mile, half-a-mile to one-mile, one mile to two-miles, and the rest of the city) around a stadium in Tshwane, South Africa on days when soccer and rugby games took place. Relative to days when the stadium was unused, findings indicated that total crime and drunk and disorderly behavior were significantly elevated up to one-mile from the stadium on game days regardless of the game outcome, but not farther away. In their study of a multipurpose arena in Charlotte, North Carolina, compared to days when the super facility was not used, Billings and Depken (2011) found an increase in property crimes up to one mile from the stadium and a significant increase in violent crimes up to two-miles away. Similarly, Marie (2016) explored London borough-level crime patterns on soccer match days and found an increase in property crime of roughly $4 \%$ for every 10,000 fans.

Kurland et al. (2014) examined patterns of violence and theft around Wembley National Stadium in London (UK) when soccer matches and other types of events (e.g. concerts took place) took place. Like the abovementioned studies, the findings indicated a change in the spatial and temporal distribution of offenses, particularly in the areas closest to (but outside) the stadium, and just before and after games took place. In addition to examining changes in the volume of crime, Kurland et al. (2014) used estimates of ambient population and ticket sales to compute changes to the rate of crime (per ambient population). They found 
that while the volume changed the rate did not, suggesting that the facility acted as a crime generator rather than an attractor.

Finally, a study by Vandiver et al. (2019) examined the influence of stadia on crime by taking advantage of the move of a "super-facility" from one location to another. In this study, the authors explored the concept of delayed exploitation, according to which offenders identify crime opportunities during a visit to a location (in this case a stadium) but exploit them at a later time (in this case, when the stadium was closed). They did this by contrasting crime rates around a stadium in the city of Ghent, Belgium, on non-match days before and after the stadium closed. Their results indicated that, relative to the period before its relocation, following the closure of the stadium, crime was lower on non-match days, suggesting evidence of a delayed exploitation effect.

Taken together there is mounting empirical evidence to suggest the influence of "superfacilities" on crime. However, various questions remain regarding their influence, particularly in terms of how this interacts with the wider constellation of smaller ("micro-") facilities, and the configuration of the street network that connects them. Below, we articulate a set of specific hypotheses that are tested in this paper, but before doing so discuss how the social fabric of an area might also influence crime.

\subsection{SOCIAL DISORGANIZATION THEORY}

Crime does not occur in a social vacuum. Indeed, theories of social disorganization argue that variation in neighborhood social structural characteristics can lower the sense of community in an area, which in turn can impact levels of crime (Shaw and McKay 1942; Bursik 1988). More specifically, the theories suggest that residents from neighborhoods with 
little sense of community (e.g., Fisse and Braithwaite 1983) are less likely to intervene to prevent crime. In contrast, in neighborhoods where social cohesion exists residents are more likely to act collectively to prevent crime (Sampson, Raudenbush, and Earls 1997).

While there are numerous variations on the theme (see Bruinsma et al., 2013), theories of social disorganization generally contend that greater population stability and resident homogeneity increase social cohesion within neighborhoods by encouraging the formation of stable social ties among community members, and increasing the likelihood that residents will share collective values and goals (Bursik, 1988; Bursik and Grasmick, 1993; Sampson and Groves, 1989).

Considerable empirical evidence provides support for social disorganization theory as an explanation for various types of crime including, but not limited to, criminal damage, theft, and violence. And, such support has been documented for analyses conducted using various spatial units of analysis to include street-segments (see Weisburd, Groff, and Yang 2012), neighborhoods (e.g. Andresen, 2006; Steenbeek and Hipp, 2011) and at higher levels of aggregations (e.g. Baudains, Braithwaite, and Johnson, 2013; Johnson and Summers, 2015).

Given the literature discussed, it was important to account for the potential influence of variation in neighborhood social (dis)organization. However, as this was not our focus, we include variables concerned with social disorganization as "control" variables rather than to allow us to test substantive hypotheses. This allows us to test for the influence of facilities and the street network on crime, having accounted for other factors expected to influence neighborhood counts of crime.

Based on the above discussion, we developed a set of expectations, which are summarized in Table I. In what follows, these are tested using data from five different UK soccer stadia 
and a spatial econometric approach that enabled an estimate of the combined influence of social and physical neighborhood-level characteristics on the distribution of crime around soccer grounds on match and non-match days. While most studies would use data for one study area, using data for more than one study area allowed us to see if the patterns observed were generalizable, at least for those locations for which data were available.

\section{TABLE I ABOUT HERE}

\section{METHODOLOGY}

\subsection{DATA}

\subsubsection{Soccer Stadia}

The study areas used here were the result of an opportunity sample provided for a separate research project funded by the Association of Chief Police Officer's whereby Villa Park (Aston Villa), Elland Road (Leeds United), Bramall Lane (Sheffield United), Hillsborough (Sheffield Wednesday) and Molineux (Wolverhampton) were selected for analysis by the funder. Using a nonprobability sample means that the empirical results cannot be confidently generalized to the wider population of stadia in England (or elsewhere). However, there was an attempt on the part of the funder to purposefully identify stadia from contrasting regions of England and different divisions within the wider "Football League" to increase the potential external validity of any findings. Two of the five study areas were located within city centers (Bramall Lane and Molineux), while the other three were not, providing variation across the study areas sampled ${ }^{2}$.

\footnotetext{
2 Discussions with ACPO lead for soccer in England and Wales, along with UK Football Policing Unit Director, and local match day police commanders for each respective area helped ensure that there had been no variation in policing tactics or crime recording policies across the different areas during the study period.
} 


\subsubsection{Match and Comparison Dates}

The websites for each stadium were used to compile a list of dates when soccer matches took place for the home team for the 2005/06 through 2009/10 seasons. These match days then guided the identification of a non-match day sample. The counterfactual days were selected to be as similar to the match days as possible in order to reduce the likelihood of confounding variables, such as day of the week or seasonal differences that might have an effect on patterns of crime (for e.g., see Brundson and Corcoran 2006; Hird and Ruparel 2007). To do this, the same day of the week seven days before and after a given match were identified. If no match occurred on either date, and if neither day had been previously selected as a comparator for another match, the earlier date was selected. However, if both dates were unavailable because a match took place on both of them, or because they were previously selected as a comparator, the search for a comparator was extended to a fourteen-day interval before and after the match. If still no suitable comparator was identified, then the search was expanded to 21 or 28 days. If no comparable non-match day could be selected for a given

match day after extending the search to 28 days the match was excluded from the sample ${ }^{3}$. As shown in Table II, in total, 1,130 days were included in the analysis (565 match and 565 comparison days). In most cases, comparison days identified were within one week of the relevant match day.

\section{TABLE II ABOUT HERE}

\footnotetext{
${ }^{3}$ To avoid any potential confounders for the clubs located in Sheffield (these clubs were $4.98 \mathrm{~km}$ apart) we eliminated potential comparison days that were match days at the other stadium as well as eliminating any other dates where alternative types of events took place at any of the relevant stadia in the study.
} 


\subsubsection{Units of Analysis}

For the analysis that follows, the unit of analysis is the UK census output area (OA). OAs are the smallest defined level of geography in the UK for which census data exist. These were selected for three reasons. First, OAs are similar in size (e.g., Andresen 2006; Johnson and Bowers 2010) or smaller (e.g., Baudains, Braithwaite, and Johnson 2013 use Lower Super Output Areas (LSOAs) containing on average 1,500 residents) than the units of analysis used in recent research on the correlates of crime at the neighborhood-level. Second, smaller units of analysis help minimize the ecological fallacy (Robinson 1950; Selvin 1958); that is, drawing inferences about an individual, or in this case a neighborhood, based on aggregate data for a larger group. In other words, using explanatory variables at the OA level is more representative of the population and characteristics of each area than if larger units of analysis (within which there may be much variation) were used. Finally, the unit of analysis is consistent with the push in research concerned with the criminology of place for the use of smaller units of analysis (Weisburd, Bruinsma, and Bernasco 2009; Oberwittler and Wikström 2009).

Previous empirical research conducted by Kurland, Johnson, and Tilley (2014) identified a change in the spatial distribution of offenses around Wembley National Stadium (in London) on soccer match days across a $3 \mathrm{~km}$ area surrounding the stadium. Guided by this finding, data were collated for all OAs $(N=1,434)$ within a $3 \mathrm{~km}$ radius of their respective stadium for: Aston Villa, $(N=284$ OAs), Leeds ( $N=216$ OAs), Sheffield United ( $N=370$ OAs; $)$, Sheffield Wednesday ( $N=289$ OAs) and Wolverhampton ( $N=275$ OAs). Each OA typically contained around 124 households, $600-800$ residents and covered an area of about $250-350 \mathrm{~m}^{2}$.

As mentioned above, features other than distance from the stadia are likely to affect where crime concentrates; consequently, propinquity to the ground is considered in combination 
with other variables. Below, we discuss the explanatory variables used and how they were analyzed. But before doing so, the dependent variable(s) are described.

\subsubsection{Police Crime Data}

Geocoded crime data for each stadium for the 2005/06 to 2009/10 seasons were provided by British Transport Police (BTP), West Midlands Police, West Yorkshire Police and South Yorkshire Police. All data were cleaned and merged, taking into account differences in recording practices between BTP and the other forces. Analyses could be conducted for a variety of crime types. In what follows, we examine patterns for those offenses that previous work suggests could plausibly be affected by activity at soccer stadia — criminal damage (to a building or vehicle), theft (all offenses that involve the taking of property from a person without the threat of or actual violence) and violent offenses (excluding robbery as this data was not readily available) —as an amalgamated category that combines these offense types. The counts of police-recorded geocoded crime events were identified using a Geographic Information System (QGIS V 1.8.0) and each OA was ascribed the corresponding count value for match and non-match days. Descriptive statistics for the total crime counts across all $\operatorname{areas}^{4}$, including the percentage of OAs that experienced one or more crimes (column two) are provided in Table III.

TABLE III ABOUT HERE

2.1.5 Routine Activity and Crime Pattern Theory Variables

Micro level risky facilities. Ordnance Survey (OS) data were obtained to determine the

\footnotetext{
${ }^{4}$ Stadium-specific crime count totals are available in Appendix 1.
} 
number of: (1) pubs, (2) fast-food restaurants, and (3) railway stations in each OA. Table III provides descriptive statistics for these variables, including the percentage of OAs that contained at least one facility (column three). To estimate potential immediate "spillover" effects (Gorman et al. 2001; Folmer and Oud 2008; Bernasco and Block 2011), that is, the influence that a particular facility located within one OA may have on crime occurring in neighboring OAs, a spatially lagged version of all three of these variables was constructed using GeoDa v1.4.6, an open-source spatial statistical package (Anselin, Syabri, and Kho 2006). A spatial weights matrix based on first-order "queen contiguity" was calculated, where two OAs were defined as being adjacent if they shared a border, or a single point. The spatial lag for each of the variables was then computed by taking the weighted average of neighboring OAs, as specified in the weights matrix. For example, for an OA that had three neighboring OAs, one of which had one pub and one of which had 3, that OA would have a spatial lag of $[(3+1+0) / 3=] 1.33$. Univariate statistics for the "spillover" effects for each respective facility type are provided in Table III $^{5}$.

"Super-facility". Street network data for each stadium area were obtained from the Ordnance Survey (OS) and the shortest network distance between each OA centroid and each respective stadium was calculated in kilometers. The shortest network distance was computed using Dijkstra's (1959) algorithm, a graph search algorithm, which solves the problem of finding the shortest path from a particular origin (in this case the OA centroid) to a specific destination node (in this case the stadium) along the street network. Table III shows the univariate statistics for this particular variable ${ }^{6}$

\footnotetext{
${ }^{5}$ Stadium-specific and facility-specific "spillover" effects are available in Appendix 2.

${ }^{6}$ Summary statistics from each OA to each specific stadium are available in Appendix 3.
} 


\section{TABLE V ABOUT HERE}

Movement Potential. Ideally, to test hypotheses, one would derive estimates of how many people visited the stadia, and more importantly, were found in each OA that surrounded them on match days. Unfortunately, while data exist regarding ticket sales, they provide no information regarding which OAs fans visit on match days. As such, alternative approaches are necessary to estimate those OAs fans are likely to travel through on match days. To this end, we draw on techniques developed in the fields of graph theory and path selection (see, Golledge, 1995) ${ }^{7}$.

Specifically, to estimate movement potential through OAs on match days, we first calculated the shortest paths (Golledge 1995) between each of the three types of facilities and the relevant stadium using Dijkstra's (1959) algorithm. Next, all of the OAs that were intersected by the shortest paths were identified and a count of the routes that passed through them computed. The counts for each type of facility were then used as estimates of movement potential generated by that type of facility for each OA (i.e., three estimates of movement potential, one for each type of facility were derived). Figure 1 illustrates how this measure was derived for each type of facility, and Table III provides descriptive statistics including the percentage of OAs that intersected at least one shortest path (column four) ${ }^{8}$.

\section{FIGURE 1 ABOUT HERE}

\footnotetext{
${ }^{7}$ Golledge (1995) conducted experimental research on path selection and route preference in human navigation. He found that compared to a variety of contending alternatives, including the simplest route or following the longest line, the shortest path is most influential in route choice selection between activity nodes (see also, Dalton, 2003).

${ }^{8}$ Descriptive statistics for each respective stadium are provided in Appendix 3.
} 


\subsubsection{Social Disorganization Variables}

Three commonly used variables - estimates of population density, ethnic diversity and population churn — were derived using data from the Office for National Statistics (ONS) 2001 Census. The first, population density was calculated by dividing the total residential population by the geographical area of each OA by a standard measure $\left(\mathrm{km}^{2}\right)$. To estimate the level of ethnic diversity for each OA, the fraction of residents that belonged to each of 15 categories of ethnic groups was first calculated ${ }^{9}$. Simpson's Index of Diversity (see Simpson 1949) computed using Eq. 1 was then used to estimate the degree of ethnic diversity in each OA:

$$
D_{i}=1-\left(\frac{\sum n_{i}\left(n_{i}-1\right)}{N_{i}\left(N_{i}-1\right)}\right)
$$

where $n_{i}$ is the total population of a particular ethnic group in area $i$, and $N_{i}$ is the total population for all ethnic groups combined in area $i . D_{i}$, is the probability that two individuals randomly selected from area $i$ will belong to a different ethnic group.

The resulting diversity score ranges between 0 (no ethnic diversity) and 1 (infinite diversity). To aid interpretation, and consistency with previous research (e.g., Baudains, Braithwaite, and Johnson 2013), these values were multiplied by ten so that a one-unit increase in the independent variable represents a ten-unit change in ethnic diversity.

\footnotetext{
${ }^{9}$ The ethnic groups used were based on the ONS classification system as follows: White British, White Irish, other White, White and Black Caribbean, White and Black African, other mixed, Indian, Pakistani, Bangladeshi, other Asian, Caribbean, African, other Black, Chinese, and other ethnic background.
} 
Population churn is based on a comparison between each individual's address on Census day (29 April 2001) with the address they stated they were living at one year prior (29 April 2000). It was estimated using Eq. 2 (Dennet and Stillwell 2008):

$$
C_{i}=\left(\frac{I_{i}+O_{i}+W_{i}}{P_{i}}\right) \times 100
$$

where $I_{i}$ is the in-migration to OA $i, O_{i}$ is the out-migration from the area, $W_{i}$ is the total migrants that move from one residence to another while remaining within the same area $i, P_{i}$ is the total population of a area $i$.

The Index of Multiple Deprivation (IMD) 2007, obtained from the UK Department for Communities and Local Government (Noble et al. 2008), was used to measure deprivation. For consistency with the index of ethnic diversity and to ease interpretation of the parameter estimates, both the estimates for population churn and the IMD were divided by ten. Table III provides summary statistics for the social disorganization variables used ${ }^{10}$.

\section{TABLE VI ABOUT HERE}

\section{ANALYTIC STRATEGY}

We employed a two-stage process. The first involved the estimation of ten stadiumspecific models $(5$ [stadia] $* 2$ [match or non-match group] $* 14$ [explanatory variables] $=140$ coefficients) to measure the relative importance of the independent variables in explaining the spatial distribution of crime on match and non-match days in the neighborhoods surrounding the stadia, but also to explicitly measure the relative significance (and difference) in effects across stadia. More specifically, Stata 15's nbreg and suest commands (StataCorp. College Station, TX) were used to estimate two negative binomial models (match and non-match day)

\footnotetext{
${ }^{10}$ Statistics for social disorganization variables for each respective area are provided in Appendix 4.
} 
simultaneously for each respective stadium ${ }^{11}$. Likelihood-ratio tests were performed to test for over dispersion, and Wald tests used to compare the equality of (each pair of) coefficients with Stata 15 's test command ${ }^{12}$.

While the analytic strategy described above is appropriate, and necessary as a first stage in the analytic process, a single, more parsimonious model that pooled each respective stadium for both sets of days was adopted for the second stage of analysis. This was employed because: (1) it increased statistical power; (2) the covariates for each individual model for all stadia for match and comparison days were similar; and (3) because there are no between stadium hypotheses, pooling each stadium in a single model provided a better approach for uncovering if there were in fact differences between match and comparison day crime and disorder patterns.

To begin, a dummy variable, $T$, was generated that specified group membership (i.e., match or non-match) along with interaction terms for group membership with the explanatory variables (e.g., match day*pub or non-match day*pub). Pooling stadia in the model by creating a series of dummy variables for each respective stadium and omitting the overall intercept term enabled the baseline to shift between stadia. The model is captured in the following equation:

$$
\begin{aligned}
C_{i}= & \beta_{1} P U B_{i}+\beta_{2} F F_{i}+\beta_{3} R A I L_{i}+ \\
& \beta_{4} P U B_{i}+\beta_{5} F F_{i}+\beta_{6} R A I L_{i} \mid \\
& \beta_{7} S N D_{i}+\beta_{8} P U B_{i \|}+\beta_{9} F F_{i \|}+\beta_{10} R A I L_{i \|}+
\end{aligned}
$$

\footnotetext{
${ }^{11}$ Models for each respective stadium are provided in Appendix 5.

${ }^{12}$ Results from these diagnostic tests (and diagnostic plots) confirmed that negative binomial models were more appropriate than Poisson equivalents (Long and Freese 2006) and that there was general consensus across each of the stadium areas in terms of direction of effect, relatively small size of the standard errors, and overall in(equality) of coefficients between match and comparison days.
} 


$$
\begin{aligned}
& \beta_{11} P T_{i}+\beta_{12} E T H_{i}+\beta_{13} I M D_{i}+\beta_{14} P D_{i}+ \\
& \beta_{15} T_{i}+\beta_{16} T_{i} * P U B_{i}+\beta_{17} T_{i} * F F_{i}+\beta_{18} T_{i} * R A I L_{i}+ \\
& \beta_{19} T_{i} * P U B_{i}+\beta_{20} T_{i} * F F_{i}+\beta_{21} T_{i} * R A I L_{i}+ \\
& \beta_{22} T_{I} * S N D_{i}+\beta_{23} T_{i} * P U B_{i}+\beta_{24} T_{i} * F F_{i \|}+\beta_{25} T_{i} * R A I L_{i \|}+ \\
& \beta_{26} T_{i} * P T_{i}+\beta_{27} T_{i} * E T H_{i}+\beta_{28} T_{i} * I M D_{i}+\beta_{29} T_{i} * P D_{i}+ \\
& \beta_{30} A V+\beta_{31} L U+\beta_{32} S U+\beta_{33} S W+\beta_{34} W W
\end{aligned}
$$

Where, $C_{i}$ is the count of crime in OA $i, P U B_{i}$ is the count of pubs in OA $i, F F_{i}$ is the count of fast-food restaurants in $\mathrm{OA} i$, and $R A I L_{i}$ is the count of rail stations in OA $i$., $P U B_{i}$ is the averaged count of pubs in the OAs surrounding $\mathrm{OA} i, F F_{i}$ is the averaged count of fast-food restaurants in the OAs surrounding $\mathrm{OA} i$, and $R A I L_{i}$ i is the averaged count of rail stations restaurants in the OAs surrounding OA $i . S N D_{i}$ is the shortest network distance between OA $i$ and the relevant stadium, $P U B_{i} \|$ is the count of shortest paths originating from pubs that travel through $\mathrm{OA} i, F F_{i}$ is the count of shortest paths originating from a fast-food restaurant that travel through OA $i, R A I L_{i} \|$ is the count of shortest paths originating from a rail station that travel through OA $i . T_{i}$ is a dummy variable for match and non-match days. $P T_{i}$ is the estimate of population turnover in $\mathrm{OA} i, E T H_{i}$ is the degree of ethnic heterogeneity in $\mathrm{OA} i$, $I M D_{i}$ is a measure of deprivation in OA $i$, and $P D_{i}$ is the estimated population density in OA i. $A V, L U, S U, S W$, and $W W$ are dummy (intercept) variables for Aston Villa, Leeds United, Sheffield United, Sheffield Wednesday and Wolverhampton Wanderers stadia respectively.

This model reduced the 140 coefficients generated in the first step of the analysis to 34 , and enables us to better identify what effects, if any, differ across the match and non-match day groups ${ }^{13}$. The second stage of analysis was conducted in R 3.1.3 (R Core Team 2015) using the MASS package (Venables and Ripley 2002).

As is clear from Table III, the variance in crime counts at the OA level exceeded the mean. Consequently, a negative binomial regression model—which increases the conditional variance of the dependent variable to account for unobserved heterogeneity (Osgood 2000) -

\footnotetext{
${ }^{13}$ One concern of the approach adopted herein is the issue of multiplicity (Type I statistical error) that occurs when making multiple comparisons. However, the stage 1 model results were largely consistent (and in line with expectation) and this regularity in itself represents a test of whether the findings are likely to reflect Type I error. For this reason, we felt that using a Bonferroni adjustment would be unnecessarily conservative (see Rothman, 1990; Savitz and Olshan 1995; Perneger 1998).
} 
was used to test hypotheses.

In addition to the problem of over-dispersion (addressed using a negative binomial model), a distinct possibility associated with the current data concerns spatial dependency. This can be problematic because most statistical tests assume that observations (and model residuals) analyzed are independent and are not systematically influenced by variables omitted from the statistical model. Where spatial autocorrelation exists, this assumption may be violated and if not corrected for can lead to errors of statistical inference (Anselin and Kelejian 1997). To assess residual spatial autocorrelation in the model, we follow the approach taken by Bernasco and Block (2011: pg. 40) and Haberman and Ratcliffe (2015) and compute the Moran's I statistic on Pearson's residuals post-estimation using a spatial weights matrix based on first order "queen" contiguity in GeoDa v1.4.6. In all cases, the Moran's I values were close to zero, and hence we consider this issue no further.

Finally, multicollinearity problems are a concern with any regression model as its presence can increase the standard errors of the estimated coefficients. This is often the case when a model includes interaction terms such as in this study. To address this, Variance Inflation Factors (VIF) ${ }^{14}$ were calculated to measure the extent to which correlation among the explanatory variables inflated the variance of the estimated regression coefficients in the model. One general rule of thumb is that VIFs greater than 10 indicate excessive multicollinearity requiring correction (Kutner et al. 2004), although some suggest that setting a particular cutoff value for VIF is arbitrary and not particularly helpful (Wooldridge 2015). Regardless, both the maximum (5.50) and mean (3.13) VIF scores were below this generally

\footnotetext{
${ }^{14}$ VIFs can be estimated using a standard or generalized method. The MASS package in R (used here) selects the relevant VIF, given the data analyzed.
} 
accepted threshold.

\section{RESULTS}

Results from the model, including interaction terms, are displayed in Table IV. For ease of interpretation, as well as the raw coefficients, we present Incidence Rate Ratios (IRR). These can be interpreted as the multiplicative effect of a one-unit change in a given variable on the dependent variable (Osgood 2000). The interaction terms require careful interpretation, so we provide an example. The IRR for pubs in the case of our model (which includes the interaction effect) has a value of 1.068 , and measures the effect of the number of pubs on the crime count for the non-match day group. The interaction coefficient (pub*match) day has a value of 1.012 and this is a measure of the difference between the effects for the match and non-match day groups, i.e., the effect for the match day group. Thus, in our model, Table IV helps guide the identification of covariates that are both significant for match and non-match days, but also differ significantly across the two types of days.

\section{TABLE IV ABOUT HERE}

To aid interpretation further, in what follows, variables of particular interest are examined more closely using average marginal effects (AMEs). The AME of a given variable conveys the rate at which the predicted number of crime events changes with respect to that covariate, all else equal. This measure is useful because (1) it is intuitive and (2) it produces a single quantity summary measure that respects both the distribution of the original data and does not rely on summarizing a substantively unobserved or unobservable covariate value (Leeper 2017).

Considering overall patterns, it is evident that there was a main effect of the "type of day", 
indicating that there was generally more crime on match than non-match days across the study areas considered. Turning to our more specific hypotheses, the results suggest that not only are crimes more likely to occur in OAs that contain pubs, but also that there is a significant difference between the effect of pubs on crime on match and non-match days (supporting Hypothesis 1). Figure 2 shows the predicted difference in the count of crime events on match versus non-match days when the number of pubs increases from one to five (the range of values in the data). Generally, the pattern highlights a significant positive association between the number of pubs in an OA and the difference in the number of crimes on match and nonmatch days ${ }^{15}$.

\section{FIGURE 2 ABOUT HERE}

Results are similar for fast-food restaurants (in support for Hypothesis 2). In this case, a slightly greater number of crimes are likely to occur in OAs that contain one or more fastfood restaurants on match days than the same OAs on non-match days. Figure 3 illustrates the extent to which these differences are significant as the number of fast-food restaurants per OA increases.

\section{FIGURE 3 ABOUT HERE}

The results do not lend support to Hypothesis 3 or 4 . That is, there is neither evidence to support a significantly elevated count of crime events in those OAs with rail stations, nor does there appear to be a significant difference in the magnitude of this effect across match and non-match day groups.

With respect to "spillover" effects, there is no evidence to suggest that areas that are

\footnotetext{
${ }^{15}$ The differences observed for OAs with more than four pubs are not significant as the $95 \%$ confidence interval extends below zero. Tables that include the AMEs for the full distribution of pubs, and other variables of interest included in our model are available upon request.
} 
contiguous to those with pubs have significantly greater counts of crime events overall or on match days in particular. For fast-food restaurants and rail stations, spillover effects are observed, but the effects are not amplified on match days.

With respect to proximity to the stadia (hypothesis 7), the findings are in line with expectation. Not only do OAs positioned closest to a stadium have the highest counts of crime, but the difference in magnitude of the effect is more pronounced on match days. Figure 4 more clearly illustrates the nature of this difference and shows that the effect decays rapidly in magnitude but persists up to about $2.5 \mathrm{~km}$ from the stadium ${ }^{16}$.

\section{FIGURE 4 ABOUT HERE}

Considering the influence of facilities on movement potential, the results provide support for Hypotheses 8 and 9. That is, the counts of crime in OAs that are situated along the shortest paths that connect a stadium to pubs and fast-food restaurants are higher on match days but not non-match days, as predicted. Figure 5 more clearly illustrates the pattern for pub to stadium movement potential, while Figure 6 shows the pattern for fast-food restaurants.

FIGURE 5 ABOUT HERE

\section{FIGURE 6 ABOUT HERE}

With respect to Hypothesis 10, there is no evidence to suggest that the influence of rail stations on movement potential is associated with counts of crime on match or non-match days.

\footnotetext{
${ }^{16}$ This result is consistent with Kurland, Tilley, and Johnson (2018) in which a custom-made non-parametric permutation approach was used to quantify the spatial extent of differences in the count of crime events across both match and non-match days.
} 
With respect to the control variables, main effects are observed for three of the four variables associated with social disorganization, but the effects do not differ for match and non-match days, as expected.

\section{DISCUSSION}

The main aim of this research was to examine the influence that "micro-" and "superfacilities" have on crime in the environments that surround them. In terms of "superfacilities", our primary focus soccer stadia have the advantage of being used episodically, and enabled us to test hypotheses using a method not unlike a natural experiment. With respect to "micro-facilities", we examined the specific influence of pubs and fast-food restaurants, since the activity in or near to areas that house such facilities is expected to be elevated, particularly on days when soccer matches are played. Recognizing the contribution that the social fabric of communities can have on crime, our statistical analyses also included control variables intended to capture key concepts of neighborhood (dis)organization. Unlike many studies, we examined patterns across multiple study areas under contrasting ecological conditions, which allowed us to test the consistency with which findings were observed. The results contribute to a developing body of research on crime and disorder associated with ("super-") facilities, as well as having broader implications for criminological theory, crime prevention practice, and for policy on the development of new facilities such as soccer stadia. We discuss each of these issues in turn.

Considering the influence of facilities on crime, there was a clear influence of the "superfacility" considered. Crime was higher in areas closest to the stadia, and this was particularly 
evident on match days. There was also clear evidence of the influence of "micro-facilities" on crime. Taking each in turn, on non-match days, crime was consistently higher in neighborhoods that contained pubs, but the effect was amplified on match days. There was, however, no evidence of a spillover effect to adjacent neighborhoods associated with pubs on match or non-match days. With respect to fast-food restaurants, crime also tended to be higher in the areas that contained these facilities, and again this effect was higher on match than nonmatch days. For this type of facility there was evidence of a spillover effect, but this was not amplified on match days. It should be noted here that we examined the influence of different types of "micro-facilities" in the aggregate. As such, we did not examine whether particular (say) pubs had a greater influence on crime, or whether the mix of various "micro-facilities" might combine in particular configurations to affect crime (Summers and Caballero 2017). Nor did we examine whether particular facilities influence particular types of crime more than others. Future research might attempt to incorporate factors that account for this variation more directly.

The above findings are in line with much of the existing research on "risky facilities" (e.g., Roncek and Bell 1981; Brantingham and Brantingham 1982; Roncek and Maier 1991; Kinney et al. 2008; Bernasco and Block 2011), providing further evidence to support routine activity and crime pattern theories. They also suggest that "super-facilities", at least in the case of soccer stadia, can have both direct effects, by increasing the rate of crime (per unit time) around them, and indirect effects, by increasing the rate of crime (per unit time) in the areas that also host micro-facilities. As discussed in the introduction, one causal mechanism for this would be that "super-facilities"-when they are open - attract more people to an area, who in turn frequent other activity nodes (such as pubs), and that this influence on activity patterns leads to the generation of crime at those locations. 
With respect to this latter point, we tested this in a more novel way by estimating how the location of the stadia and "micro-facilities" might influence the movement potential of people on match days. Here, we found clear evidence that on match days the rate of crime (per unit time) tended to be higher in those areas with the highest estimated movement potential for routes that would originate from pubs and fast-food restaurants and terminate at the stadia. These results are particularly compelling given that the effect was clearly selective — only being observed on match days, as predicted. The multivariate framework employed means that the effects discussed above were above and beyond the influence of proximity to the stadia and other factors. To our knowledge, this is the first study to test (and demonstrate) how changes in the estimated movement potential of people between routine activity nodes might affect crime risk under contrasting ecological conditions. Since this movement potential is affected by the configuration of the street network, our findings also speak to an expanding literature on the role that the street network plays in crime pattern formation (e.g., Beavon et al. 1994; Davies and Johnson 2015; Summers and Johnson 2016; Frith, Johnson and Fry 2017).

It is perhaps surprising that in contrast to the other facilities considered, the presence of rail stations in an area appeared to have no effect on the spatial distribution of crime. One possible explanation for this difference is that pubs and fast-food restaurants add something else to promote crime that rail stations do not, be it providing alcohol or a meeting place (arranged or coincidental) where crime occurs. Another possible explanation is that the increased mutual guardianship and natural surveillance brought on by the in- and out-flow of passengers on both match and non-match days found in these neighborhoods is sufficient to suppress opportunities for crime at rail stations (see, Jacobs 1961). Further, it may be that this increased in- and out-flow of passengers/fans is at a particular rate (per unit time) on 
match days that makes the route(s) between a given rail station and stadium safer than at these alternative facilities. In other words, this may suggest that, all else equal, the presence of a high number of other soccer fans, CCTV, ticket barriers, and police who may position themselves at railway stations and along the routes that connect them to stadia on match days (in anticipation of trouble) is sufficient to reduce crime; however, this may do nothing to deter opportunities for crime in the adjacent neighborhoods that are not necessarily intersected by the paths that link railway stations to a stadium. It should also be noted that the police often adopt a "funneling" approach to usher supporters to the stadium, which could explain why the routes that most directly connect rail stations to these stadia do not appear to experience a significant increase in crime. Future research might seek to disentangle the comparative influence of the police and informal guardians (such as fans) at railway stations (or other facilities) on crime using observational methods. It is also possible that the underlying patterns that emerged more generally were influenced by "micro-facilities" that were not included in the model but that had a protective effect. Future research might examine this issue too.

We now turn attention to the practical implications of the findings in this article (at least for these five study areas). Police resources are limited and so patrolling areas (and those nearby) that contain risky facilities may be unrealistic in many cases. Moreover, it may be inefficient since doing so would mean that other activities would have to be foregone. However, where there exist "super-facilities" with predictable episodic use (e.g., stadia or other large entertainment facilities) the police might reasonably prioritize the areas that contain them and the routes along which movement potential is most likely to be elevated on those days and times the "super-facilities" are in use (or just before and after these times). 
Consideration might also be given to targeted crime prevention interventions. For instance, continuing with our current examples, those pubs that are situated along the most problematic routes on (soccer) match days might use plastic-ware before, during, and after matches instead of glassware (see Shepherd 1994; Warburton and Shepherd 2000; Cusens and Shepherd 2005). Eliminating the use of glassware from such pubs, may reduce the chance and severity of violence, and also reduce the potential for glassware to be used as missiles that cause criminal damage to buildings and vehicles in the area. Further interventions might strengthen formal surveillance, using mounted police or by introducing temporary, moveable CCTV along these paths.

Our findings also have implications for urban planning. If, as our findings suggest, "superfacilities" do have both direct and indirect effects on crime in the neighborhoods that surround them, then consideration should be given as to where they are located, the characteristics of the surrounding neighborhoods, and the locations of nearby "micro-facilities". To elaborate, criminogenic effects might be minimized in areas where the constellation of "micro-facilities" is likely to contain movement potential to a few corridors that can easily be policed either formally or informally ${ }^{17}$. More generally, when new "super-facilities" (in particular) are proposed it would be sensible for those responsible for planning decisions to undertake what Ekblom $(1997,2001)$ and Bowers (2014) refer to as a crime-impact assessment. Such an assessment would take account of findings including those presented here.

Of course, caution should be exercised in generalizing the findings reported here. It is possible that the results observed here may not apply to stadia, or other "super-facilities"

\footnotetext{
${ }^{17}$ We did not test theories of social disorganization here, but the results suggest that crime was lower in areas with community characteristics that are associated with social control. As such, in locating facilities, account might be taken of the social fabric of communities as well as their physical characteristics.
} 
elsewhere. However, the inclusion of five stadia here, rather than a single case study, and the consistency of the results in the first step of our analysis, do suggest that there is some degree of external validity to our findings. The findings, of course, represent a mere snapshot of two times, match and non-match days, without consideration to stadium capacity or to any temporal variation (i.e., kickoff times, daylight, day of the week, season of the year, etc.) factors that have been shown to influence crime patterns elsewhere (Bowers and Tompson 2013; Tompson and Bowers 2015). Future research should attempt to account for these factors. Equally important, is the familiar caveat that correlation does not imply causation; however, the (natural) experimental nature of the research reported does inspire more confidence than other research designs would.

A further potential consideration concerns the increased police presence that is routinely provided on match days. Numerous studies have found that community policing schemes that involve the deployment of an increased police presence in crime hotspots (for a review, see Braga et al. 2014) lead to increases in crime detection rates. It is thus possible that the elevated rates in crime observed on match days are due to the better recording of crime. However, previous observational research on policing at soccer matches - at least in the UK-suggests that this is unlikely to be the case. This is because at soccer matches, the police view their primary function as maintaining public order, and consequently are reluctant to make arrests even if criminal violations occur, as this would reduce their capacity to maintain order (Kurland et al. 2011b). This does, however, lead to a necessary caveat regarding data limitations. More specifically, given the shift in the emphasis to maintaining public order by the police on match days, there may be some systematic underreporting of incidents that would typically result in an arrest. Given this, our results might be considered conservativeactual crime and disorder patterns may be greater than what was captured herein. 
To summarize, using a multivariate spatial regression, this article provides further evidence to support routine activity, and crime pattern theories in explaining the spatial distribution of crime and disorder. More importantly, we make use of conditions akin to a natural experiment to illustrate the role that "super-facilities" play in shaping the distribution of crime at, around and along the routes to and from such activity nodes, and how these facilities amplify the influence of smaller nearby "risky" facilities in crime pattern formation. 


\section{REFERENCES}

Anselin L, Bera AK, Florax R, Yoon MJ (1996) Simple diagnostic tests for spatial dependence. Reg Sci Urban Econ 26:77—104

Anselin L, Syabri I, Kho Y (2006) GeoDa: an introduction to spatial data analysis. Geogr Anal 38:5-22

Anselin L, Kelejian HH (2007) Testing for spatial error autocorrelation in the presence of endogenous regressors. Int Regional Sci Rev 20: 153—182

Baudains P, Braithwaite A Johnson SD (2013) Target choice during extreme events: A discrete spatial choice model of the 2011 London riots. Criminol $51: 251--285$

Beavon DJK, Brantingham PL, Brantingham PJ (1994) The influence of street networks on the patterning of property offenses. Crime Prev Studies 2: $115-148$

Bernasco W (2013) Offenders on offending: Learning about crime from criminals. Routledge

Bernasco W, Block R (2011) Robberies in Chicago: a block-level analysis of the influence of crime generators, crime attractors, and offender anchor points. J Res Crime and Delinq 48: $33-57$

Billings S, Depken CA (2011) Sports Events and Criminal Activity: A Spatial Analysis. In Violence and Aggression in Sporting Contests: Economics, History, and Policy, edited by RT Jewell. Berlin: Springer Publishing.

Bowers K. (2014) Risky facilities: crime radiators or crime absorbers? A comparison of internal and external levels of theft. J Quant Criminol 30:389—414

Bowers KJ, Tompson L (2013) A Stab in the Dark? Analysing Temporal Trends of Street Robbery. J Res in Crim Delinq 50(4), 616-631

Braga AA, Clarke RV (2014) Explaining high-risk concentrations of crime in the city: Social disorganization, crime opportunities, and important next steps. J Res Crime Delinq 51(4), 480-498

Braga AA, Papachristos AV, Hureau DM (2014) The effects of hot spots policing on crime: An updated systematic review and meta-analysis. Jus Quar 31(4), 633-663

Brantingham PL, Brantingham PJ (1993) Nodes, paths and edges:

Considerations on the complexity of crime and the physical environment. J Environ Psychol 13:3-28 
Brantingham PL, Brantingham PJ (1995) Criminality of place: Crime Generators and Crime Attractors. Eur J Crim Pol Re 3:5-26

Breetzke G, Cohn EJ (2013) Sporting events and the spatial patterning of crime in South Africa: Local interpretations and international implications. Can J of CriminolCrim $55: 387-420$

Brunsdon C, Corcoran J (2006) Using circular statistics to analyse time patterns in crime incidence. Comput Environ Urban 30:300-319

Cameron AC, Trivedi PK (1990) Regression-based tests for overdispersion in the Poisson model. J Econometrics 46:347-364

Campaniello N. (2013) Mega Events in Sports and Crime: Evidence from the 1990 Football World Cup. J Sport Econ 14: 148-170.

Cohen LE, Felson M (1979) Social change and crime rate trends: A routine activity approach. Am Sociol Rev 588-608

Conroy-Dalton R, Bafna S (2003) The syntactical image of the city: A reciprocal definition of spatial elements and spatial syntaxes

Cusens B, Shepherd J (2005) Prevention of alcohol-related assault and injury. Hospital medicine (London, England: 1998) 66:346-348

Davies T. Johnson SD (2015) Examining the relationship between road structure and burglary risk via quantitative network analysis. J Quant Criminol 31: $481-507$

Dijkstra EW (1959) A note on two problems in connexion with graphs. Numerische mathematik 1:269-271

Eck JE (1994) Drug Markets and Drug Places: A Case-control Study of the Spatial Structure of Illicit Drug Dealing. University of Maryland, Faculty of the Graduate School.

Ekblom P (1997) Gearing up against crime: A dynamic framework to help designers keep up with the adaptive criminal in a changing world. Int J Risk Sec and Crim Prev 249266

Ekblom P (2001) Future imperfect: Preparing for the crimes to come 38-40

Felson M (1986) Routine activities, social controls, rational decisions, and criminal outcomes. The reasoning criminal 302-327

Fisse B, Braithwaite J (1983) The impact of publicity on corporate offenders. SUNY Press

Folmer H, Oud J (2008) How to get rid of W: a latent variables approach to modelling spatially lagged variables. Environ Plann A 40:2526-2538 
Frith MJ, Johnson SD Fry HM (2017) Role of the street network in burglars' spatial decision-making. Crim 55(2), pp.344-376

Golledge RG (1995) Path selection and route preference in human navigation: A progress report. In International Conference on Spatial Information Theory, pp. 207-222. Springer Berlin Heidelberg

Gorman DM, Speer PW, Gruenewald PJ Labouvie EW (2001) Spatial dynamics of alcohol availability, neighborhood structure and violent crime. J Stud Alcohol 62:628 - 636

Groff ER, Lockwood B (2014) Criminogenic facilities and crime across street segments in Philadelphia uncovering evidence about the spatial extent of facility influence. J Res Crime Delinq. 51:277-314

Grubesic TH, Pridemore WA, Williams DA, Philip-Tabb L (2013) Alcohol outlet density and violence: the role of risky retailers and alcohol-related expenditures. Alcohol Alcoholism. 48:613-619

Haberman CP, Ratcliffe, JH (2015) Testing for temporally differentiated relationships among potentially criminogenic places and census block street robbery counts. Criminol 53(3), 457-483

Hillier B, Sahbaz O (2009) Crime and Urban Design: An Evidence-based Approach. Designing sustainable cities 163

Hird C, Ruparel C. (2007) Seasonality in recorded crime: Preliminary findings. London, England: Home Office

Jacobs J. (1961) The death and life of great American cities. Vintage

Jennings JM, Milam AJ, Greiner A, Furr-Holden CDM., Curriero FC, Thornton RJ (2014) Neighborhood alcohol outlets and the association with violent crime in one midAtlantic City: The implications for zoning policy. J Urban Health 91:62-71

Johnson LT,Ratcliffe JH (2014) A partial test of the impact of a casino on neighborhood crime. Secur J 30(2), 437-453

Johnson SD, Bowers KJ (2010) Permeability and burglary risk: are cul-de-sacs safer? J. Quant Criminol 26:89-111

Johnson, S.D., and Summers, L. 2015. Testing ecological theories of offender spatial decision making using a discrete choice model. Crim Delinq 61:454--480.

Kurland J (2019) Arena-based events and crime: an analysis of hourly robbery data. App Econ, 51(36), 3947-3957. 
Kurland J, Johnson SD, Tilley N (2011b) An analysis of the Spatio-temporal 'footprint' in and around Aston Villa (Villa Park). Association of Chief Police Officers.

Kurland J, Johnson SD, Tilley N (2011a) An analysis of the Spatio-temporal 'footprint' in and around Leeds United (Elland Road). Association of Chief Police Officers.

Kurland, J, Johnson SD Tilley N (2014) Offenses around stadiums: A natural experiment on crime attraction and generation. J Res Crime Deling 51:5-28

Kurland J, Johnson SD, Tilley N (2017) Hotspotting and football violence: Current statistics and implications for prevention. In The Wiley Handbook of Violence and Aggression, $1-15$.

Kurland J, Tilley N, Johnson SD (2018) Football pollution: an investigation of spatial and temporal patterns of crime in and around stadia in England. Sec J $1-20$

Kutner MH, Nachtsheim C Neter J (2004) Applied linear regression models. McGrawHill/Irwin

LaGrange TC, Silverman RA (1999) Low self-control and opportunity: Testing the general theory of crime as an explanation for gender differences in delinquency. Criminol 37: $41-72$

Leeper TJ (2017) Interpreting Regression Results using Average Marginal Effects with R's margins

Liao TF (1994) Interpreting probability models: Logit, probit, and other generalized linear models. No. 101. Sage

Long JS, Freese J (2006) Regression models for categorical dependent variables using Stata. Stata press

Marie O (2016) Police and thieves in the stadium: measuring the (multiple) effects of football matches on crime. J Roy Stat Soc: Series A (Statistics in Society), 179(1), 273292.

McCord ES, Ratcliffe JH (2007) "A micro-spatial analysis of the demographic and criminogenic environment of drug markets in Philadelphia." Aust N J Criminol 40, 1: $43-63$

Miethe TD, Meier RF (1990) Opportunity, choice, and criminal victimization: A test of a theoretical model. J Res Crime Delinq 27:243-266

Munyo I, M. Rossi M (2013) Frustration, Euphoria, and Violent Crime. J Econ Beh Org 89: 136-142.

Noble M, McLennan D, Wilkinson K, Whitworth A, Exley S, Barnes H, Dibben C, McLennan D (2007) The English indices of deprivation 2007 
Oberwittler D, Wikström PO (2009) Why small is better: Advancing the study of the role of behavioral contexts in crime causation. In Putting Crime in its Place, pp. 35-59. Springer New York

Osgood WD (2000) Poisson-based regression analysis of aggregate crime rates. J Quant Criminol 16: 21—43

Perneger TV (1998). What's wrong with Bonferroni adjustments. BMJ (Clinical research ed.), 316(7139), 1236-1238.

Premier League. (2005) National fan survey. London

Premier League. (2006) National fan survey. London

Premier League. (2007) National fan survey. London

Premier League. (2008) National fan survey. London

Propheter G (2019) Do urban sports facilities have unique social costs? An analysis of event-related congestion on police response time. Int J Urb Sci, 1-11.

Ratcliffe JH (2012) The spatial extent of criminogenic places: a changepoint regression of violence around bars. Geogr Anal 44:302-320

Rengert GF, Wasilchick J (2000) Suburban burglary: A tale of two suburbs. Springfield: Charles C. Thomas

Rice KJ, Csmith WR (2002) Socioecological models of automotive Theft: Integrating routine activity and social disorganization approaches. J Res Crime Delinq 39: $304-336$

Robinson WS (1950) Ecological correlations and the behavior of individuals. Am Sociol Rev 15: 351-357

Roman CG (2005) Routine activities of youth and neighborhood violence: Spatial modeling of place, time, and crime." Geographic Information Systems and Crime Analysis. Hershey, PA: Idea Group Publishing 293-310

Roncek DW, LoBosco A (1983) The effect of high schools on crime in their neighborhoods. Soc Sci Quart 64: 598

Roncek DW,Bell R (1981) Bars, blocks, and crimes. J of Env Sys 11:35-47

Roncek DW, Maier PA (1991) Bars, blocks, and crimes revisited: Linking the theory of routine activities to the empiricism of "hot spots". Criminol 29:725-753 
Rossmo DK, Laverty I Moore B (2005) Geographic profiling for serial crime investigation. Geographic Information Systems and Crime Analysis. Hershey, PA: Idea Group Publishing 137-152

Rothman KJ (1990) No adjustments are needed for multiple comparisons. Epidemiol. 1:4346.

Sampson RJ (2012) Great American city: Chicago and the enduring neighborhood effect. University of Chicago Press

Sampson RJ, Raudenbush SW (1999) Systematic social observation of public spaces: A new look at disorder in urban Neighborhoods 1. Am J Sociol 105: 603-651

Savitz DA, Olshan AF (1995) Multiple comparisons and related issues in the interpretation of epidemiologic data. Am J Epidemiol. 142:904-908

Sarmiento-Barbieri I, Ge Q, Schneider R (2018) Emotional Cues and Crime: Spatial and Temporal Evidence from Brazilian Soccer Games. Available at SSRN 3289286.

Selvin HC (1958) Durkheim's suicide and problems of empirical research. Am J Sociol 607-619

Shaw CR, McKay HD (1942) Juvenile Delinquency and Urban Areas. Chicago, IL: University of Chicago Press

Shepherd J (1994) Violent crime: the role of alcohol and new approaches to the prevention of injury. Alcohol Alcoholism 29:5-10

Simpson EH (1949) Measurement of diversity. Nature

Summers L, Caballero M (2017) Spatial conjunctive analysis of (crime) case configurations: Using Monte Carlo methods for significance testing. App Geo, 84, 55-63.

Summers L, Johnson SD (2016) Does the Configuration of the Street

Network Influence Where Outdoor Serious Violence Takes Place? Using Space Syntax to Test Crime Pattern Theory. J Quant Criminol 1-24

Taylor RB (2015) Community Criminology: Fundamentals of Spatial and Temporal Scaling, Ecological Indicators, and Selectivity Bias. New York: New York University Press

Tompson LA, Bowers K J (2015) Testing time-sensitive influences of weather on street robbery. Crim Sci, 8 (4).

Townsley M, Sidebottom A (2010) All offenders are equal, but some are more equal than others: Variation in journeys to crime between offenders. Criminol 48:897-917 
Vandeviver C, Bernasco W, Van Daele S (2019) Do sports stadiums generate crime on days without matches? A natural experiment on the delayed exploitation of criminal opportunities. Sec J, 32(1), 1-19.

Venables WN, Ripley, BD (2002) Random and mixed effects. In Modern Applied Statistics with S, pp. 271-300. Springer New York

Vuong QH (1989) Likelihood ratio tests for model selection and non-nested hypotheses. Econometrica 307-333

Warburton AL, Shepherd JP (2000) Effectiveness of toughened glassware in terms of reducing injury in bars: a randomised controlled trial. Inj Prev $6: 36-40$

Weisburd D. (2014) The law of crime concentration and the criminology of place. Criminol 53:133-157

Weisburd D., Groff ER, Yang S (2012) The criminology of place: Street segments and our understanding of the crime problem. Oxford University Press

Wilcox P, Eck JE (2011) Criminology of the unpopular. Criminol Pub Pol 10:473 — 482

Wooldridge J.M (2015) Introductory econometrics: A modern approach. Nelson Education

Wortley R (1997) Reconsidering the Role of Opportunity in Situational Crime Prevention. In: G. Newman, RV Clarke and SG Shohan (eds.), Rational Choice and Situational Crime Prevention. Aldershot, UK: Ashgate Publishing

Yang Z, Hardin JW, Addy CL, Vuong, QH (2007) Testing approaches for overdispersion in Poisson regression versus the generalized Poisson model. Biometrical J 49:565-584

Zipf GK (1949) Human behavior and the principle of least effort. Cambridge, MA:Addison-Welsey 
Table I. Summary of hypotheses (H) and control variables (C) organized by theoretical perspective and variable category.

\begin{tabular}{|c|c|c|}
\hline $\begin{array}{l}\text { Theoretical } \\
\text { Perspective }\end{array}$ & $\begin{array}{l}\text { Variable } \\
\text { Categories }\end{array}$ & Hypothesis \\
\hline \multirow{4}{*}{$\begin{array}{l}\text { Routine } \\
\text { Activity and } \\
\text { Crime Pattern } \\
\text { Theories }\end{array}$} & $\begin{array}{l}\text { "Micro-Level" } \\
\text { Risky Facility }\end{array}$ & $\begin{array}{l}\text { Crimes are more likely to occur in areas that contain pubs (H1), fast-food } \\
\text { restaurants }(\mathrm{H} 2) \text { or transportation nodes }(\mathrm{H} 3) \text {. This will be the case on any } \\
\text { type of day, as such facilities attract people regardless of whether soccer } \\
\text { matches are played, however the effects will be larger on match days due to } \\
\text { increased use. }\end{array}$ \\
\hline & $\begin{array}{l}\text { "Micro-Level" } \\
\text { Risky Facility } \\
\text { "Spillover" }\end{array}$ & $\begin{array}{l}\text { Crimes are more likely to occur in areas that are contiguous to areas with } \\
\text { pubs (H4), fast-food restaurants (H5) or transportation nodes (H6). This will } \\
\text { be the case on any type of day, as such facilities attract people regardless of } \\
\text { whether soccer matches are played, however the effects will be larger on } \\
\text { match days due to increased use. }\end{array}$ \\
\hline & "Super-Facility” & $\begin{array}{l}\text { On match days only, crimes are more likely to occur in those areas that are } \\
\text { closer to the stadium than those that are situated farther from the ground } \\
\text { (H7). }\end{array}$ \\
\hline & $\begin{array}{l}\text { Movement } \\
\text { Potential }\end{array}$ & $\begin{array}{l}\text { The effect of those areas that intersect the shortest paths between an area } \\
\text { containing pubs (H8), fast-food restaurants (H9), and transportation nodes } \\
\text { (H10) and the stadium where the match is taking place on match days will } \\
\text { be larger than the effect on non-match days due to increased use. }\end{array}$ \\
\hline $\begin{array}{l}\text { Social } \\
\text { Disorganization } \\
\text { Theory }\end{array}$ & Control Variables & $\begin{array}{l}\text { Crimes are more likely to occur in areas with higher residential population } \\
\text { density (C1), higher population turnover (C2), greater ethnic diversity (C3), } \\
\text { and in areas with higher levels of deprivation (C4), but these effects are } \\
\text { expected to be constant on match- and non-match days (C5). }\end{array}$ \\
\hline
\end{tabular}


Table II. Summary of match and comparison day samples.

\begin{tabular}{lrrrrc}
\hline & $\begin{array}{c}\text { Aston } \\
\text { Villa }\end{array}$ & $\begin{array}{c}\text { Leeds } \\
\text { United }\end{array}$ & $\begin{array}{c}\text { Sheffield } \\
\text { United }\end{array}$ & $\begin{array}{c}\text { Sheffield } \\
\text { Wednesday }\end{array}$ & $\begin{array}{c}\text { Wolver- } \\
\text { hampton }\end{array}$ \\
\hline Total Match Days & 116 & 138 & 127 & 126 & 124 \\
7 Day Comparison & 77 & 125 & 65 & 63 & 122 \\
14 Day Comparison & 14 & 10 & 12 & 14 & 2 \\
21 Day Comparison & 8 & 3 & 10 & 13 & 0 \\
28 Day Comparison & 5 & 0 & 14 & 8 & 0 \\
Total Comparison Days Identified & 104 & 138 & 101 & 98 & 124 \\
\hline
\end{tabular}


Table III. Univariate statistics for study variables.

\begin{tabular}{|c|c|c|c|c|c|c|c|}
\hline Variable & $\begin{array}{c}\% \text { OAs } \\
\text { with } \\
\text { Crime }\end{array}$ & $\begin{array}{c}\text { \%OAs } \\
\text { with } \\
\text { Facility }\end{array}$ & $\begin{array}{c}\text { \%OAs } \\
>0 \\
\text { movement }\end{array}$ & Mean & SD & Min & Max \\
\hline \multicolumn{8}{|l|}{ Crime Counts $^{\mathrm{a}}$} \\
\hline Match & 97.00 & & & 10.81 & 31.18 & .00 & 812.00 \\
\hline Comparison & 98.00 & & & 9.47 & 27.33 & .00 & 730.00 \\
\hline Total & 98.00 & & & 10.14 & 29.32 & .00 & 812.00 \\
\hline \multicolumn{8}{|l|}{ "Micro-level" Risky Facility ${ }^{\mathrm{b}}$} \\
\hline Pubs & & .11 & & .24 & 1.50 & .00 & 32.00 \\
\hline Fast-food Restaurants & & .15 & & .31 & 1.38 & .00 & 34.00 \\
\hline Railway Stations & & .01 & & .01 & 0.15 & .00 & 3.00 \\
\hline \multicolumn{8}{|c|}{ "Micro-level" Risky Facility "Spillover" } \\
\hline Pubs & & & & .31 & .94 & .00 & 13.33 \\
\hline Fast-food Restaurants & & & & .39 & 69 & .00 & 8.75 \\
\hline Railway Stations & & & & .01 & .06 & .00 & 1.00 \\
\hline \multicolumn{8}{|l|}{ "Super-Facility" } \\
\hline OA to stadium & & & & 2376.55 & 838.06 & 128.22 & 4410.05 \\
\hline \multicolumn{8}{|l|}{ Movement Potential } \\
\hline Pub-to-stadium & & & 48.00 & 3.46 & 13.45 & .00 & 191.00 \\
\hline Fast-food-to-stadium & & & 51.00 & 4.08 & 12.22 & .00 & 174.00 \\
\hline Rail-to-stadium & & & 7.00 & .08 & .39 & .00 & 6.00 \\
\hline \multicolumn{8}{|l|}{ Controls } \\
\hline Population turnover & & & & 1.63 & 1.22 & .15 & 9.62 \\
\hline Ethnic heterogeneity & & & & 2.97 & 2.18 & .00 & 7.45 \\
\hline IMD & & & & 3.87 & 1.87 & .35 & 7.68 \\
\hline Residential Population Density & & & & 7283.12 & 5018.60 & 271.00 & 60645.00 \\
\hline
\end{tabular}

${ }^{a}$ All dependent variables are output area (OA) counts (Match Day $N=15,508$; Comparison Day $N=13,594$ ).

${ }^{\mathrm{b}}$ Output Area counts for each type of facility.

"All "spillover" variables are a function of a queen contiguity weight average to capture the degree of presence of a particular facility in neighboring OAs.

ABBREVIATION: $\mathrm{SD}=$ standard deviation 
Table IV. Negative binomial model with interactions for output areas around five stadia.

\begin{tabular}{|c|c|c|c|c|c|c|c|}
\hline \multirow[b]{2}{*}{ Variable } & \multicolumn{3}{|c|}{ Comparison Day Effect } & & \multicolumn{3}{|c|}{ Interaction Effect } \\
\hline & $b$ & $(\mathrm{SE})$ & IRR & & $b$ & (SE) & IRR \\
\hline \multicolumn{8}{|l|}{ "Micro-level" Risky Facility } \\
\hline Pubs & $.069 * * *$ & $(.010)$ & $1.068 * * *$ & & $.012 *$ & $(.002)$ & $1.012 *$ \\
\hline Fast-food & $.076 * * *$ & $(.015)$ & $1.079 * * *$ & & $.016^{*}$ & $(.003)$ & $1.016^{*}$ \\
\hline Rail stations & -.087 & $(.094)$ & .916 & & -.061 & $(.185)$ & .940 \\
\hline \multicolumn{8}{|l|}{ "Micro-level" Risky Facility "Spillover" } \\
\hline Pubs & .031 & $(.022)$ & 1.031 & & -.002 & $(.044)$ & .999 \\
\hline Fast-food & $.112 * *$ & $(.039)$ & $1.118 * *$ & & -.544 & $(.055)$ & .947 \\
\hline Rail stations & $1.451 * *$ & $(.194)$ & $4.271^{* *}$ & & -.228 & $(.556)$ & .769 \\
\hline \multicolumn{8}{|l|}{ "Super-Facility" } \\
\hline OA to stadium $(\mathrm{km})$ & $-.056^{*}$ & $(.025)$ & $.997 *$ & & $-.085 * * *$ & $(.030)$ & $.999 * * *$ \\
\hline \multicolumn{8}{|l|}{ Movement Potential } \\
\hline Pub-to-stadium & -.003 & $(.002)$ & .997 & & $.005^{*}$ & $(.001)$ & $1.005^{*}$ \\
\hline Fast-food-to-stadium & .003 & $(.003)$ & 1.003 & & $.005^{*}$ & $(.002)$ & $1.005^{*}$ \\
\hline Rail-to-stadium & .034 & $(.057)$ & 1.035 & & .107 & $(.079)$ & 1.113 \\
\hline \multicolumn{8}{|l|}{ Controls } \\
\hline Population turnover & $.159 * * *$ & $(.018)$ & $1.172 * * *$ & & -.040 & $(.250)$ & .960 \\
\hline Ethnic heterogeneity & .012 & $(.013)$ & 1.012 & & -.002 & $(.012)$ & .998 \\
\hline IMD & $.176^{* * *}$ & $(.011)$ & $1.192 * * *$ & & .006 & $(.015)$ & 1.006 \\
\hline Residential Population Density (*.001) & $-.049 * * *$ & $(.004)$ & $.999 * * *$ & & .0007 & $(.005)$ & .999 \\
\hline \multicolumn{8}{|l|}{ Type of Day } \\
\hline \multirow[t]{2}{*}{ Match or Comparison Group } & $.094 * * *$ & $(.026)$ & $1.098 * * *$ & \multirow{2}{*}{\multicolumn{2}{|c|}{ Moran's I }} & & \\
\hline & & & & & & & \\
\hline Stadium intercepts & & & & Match & Comparison & & \\
\hline Aston Villa & $1.274 * * *$ & $(.091)$ & $3.577 * * *$ & $.01 *$ & $-.01 *$ & & \\
\hline Leeds United & $1.841 * * *$ & $(.077)$ & $6.304 * * *$ & $.03 *$ & $-.02 *$ & & \\
\hline Sheffield United & $1.351 * * *$ & $(.075)$ & $3.863 * * *$ & $.01 *$ & $.05^{*}$ & & \\
\hline Sheffield Wednesday & $1.456^{* * *}$ & $(.067)$ & $4.292 * * *$ & $.02 *$ & $.06^{*}$ & & \\
\hline Wolverhampton Wanderers & $1.364 * * *$ & $(.080)$ & $3.913 * * *$ & $.03 *$ & $.04 *$ & & \\
\hline \multicolumn{8}{|l|}{ Diagnostics } \\
\hline Lnalpha & & -1.07 & & & & & \\
\hline
\end{tabular}

Note: ${ }^{*} \mathrm{p}<0.05,{ }^{* *} \mathrm{p}<0.01, * * * \mathrm{p}<0.001$. 
Figure 1. Example of the shortest network distance (SND) approach to estimating movement potential between "micro-facilities" (pubs in this example) and the relevant stadium.

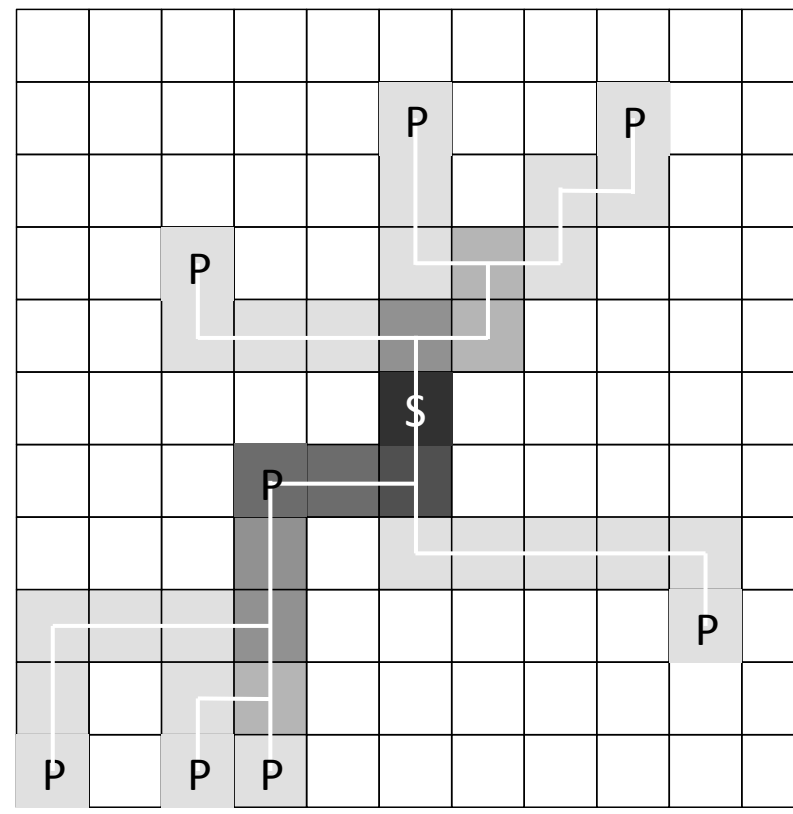

\section{LEGEND}

$S$ - stadium

P - pub

$\square-0$

$\square-1$

$\square-2$

$\square-3$

$\square-4$

- 5

$\square-8$ 
Figure 2. Average Marginal Effects of pubs on expected crime event counts in an OA for match days.

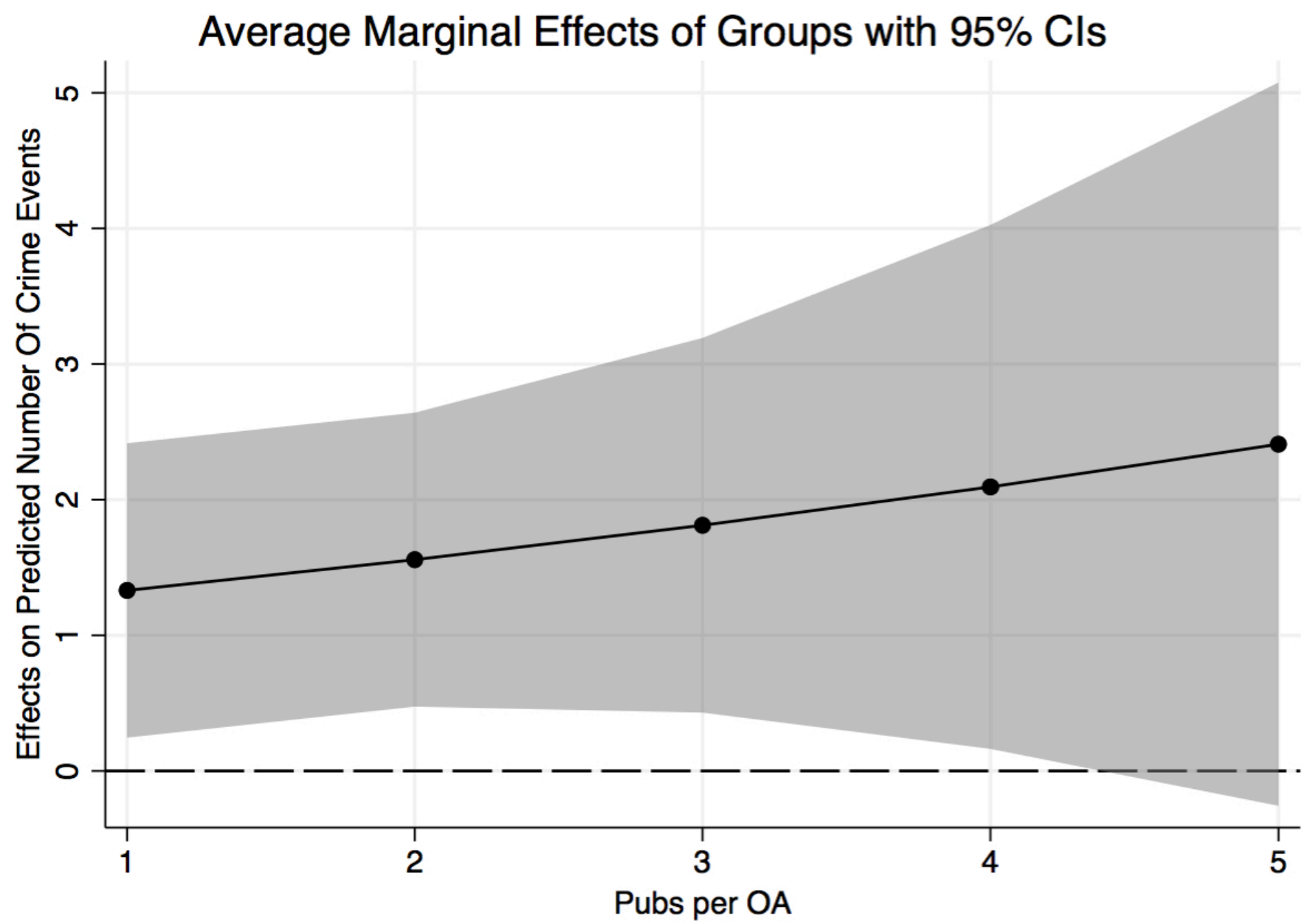


Figure 3. Average Marginal Effect of fast-food restaurants on expected crime event counts in an OA for match days.

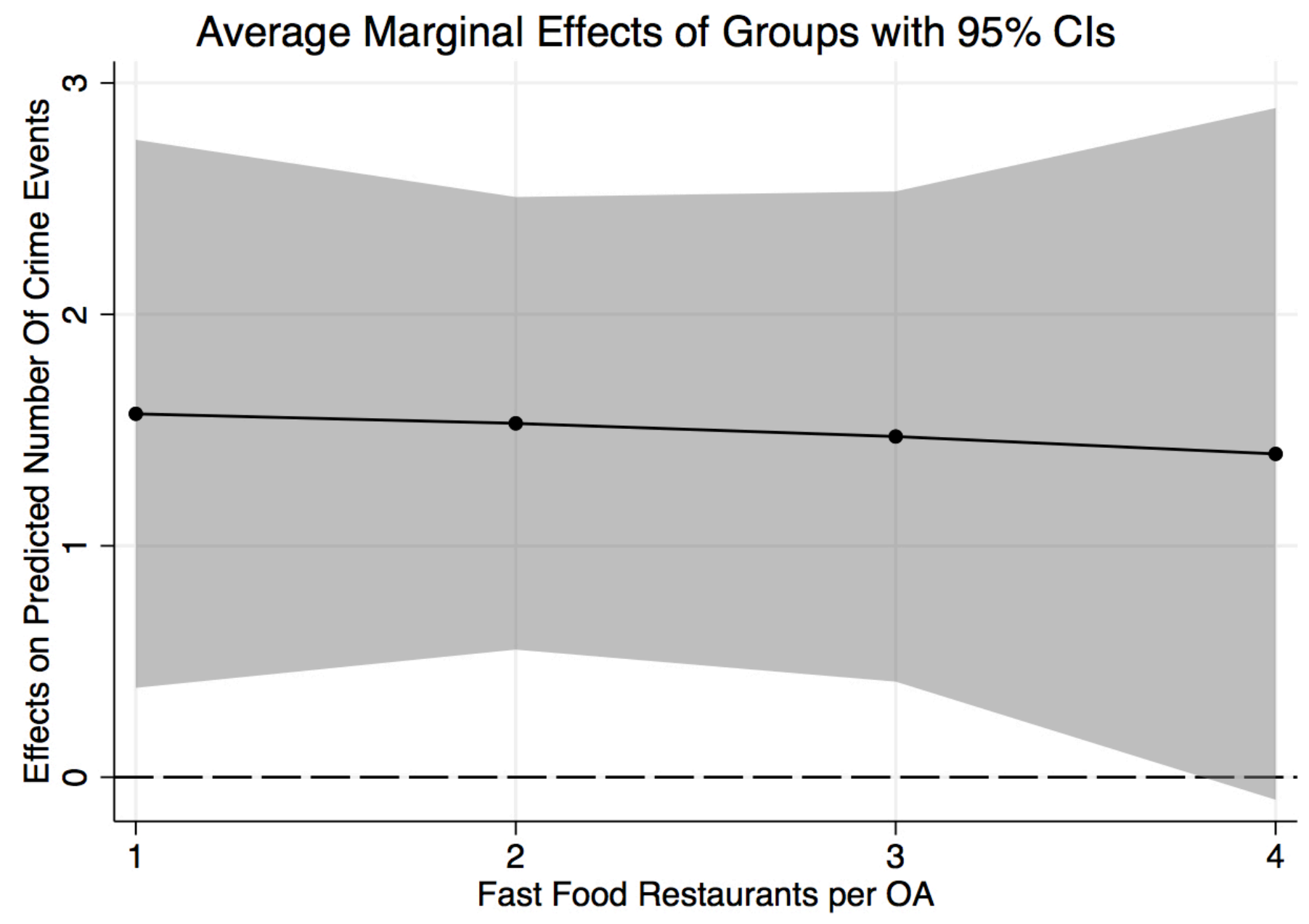


Figure 4. Average Marginal Effect of OA to stadium propinquity on crime event counts for match days.

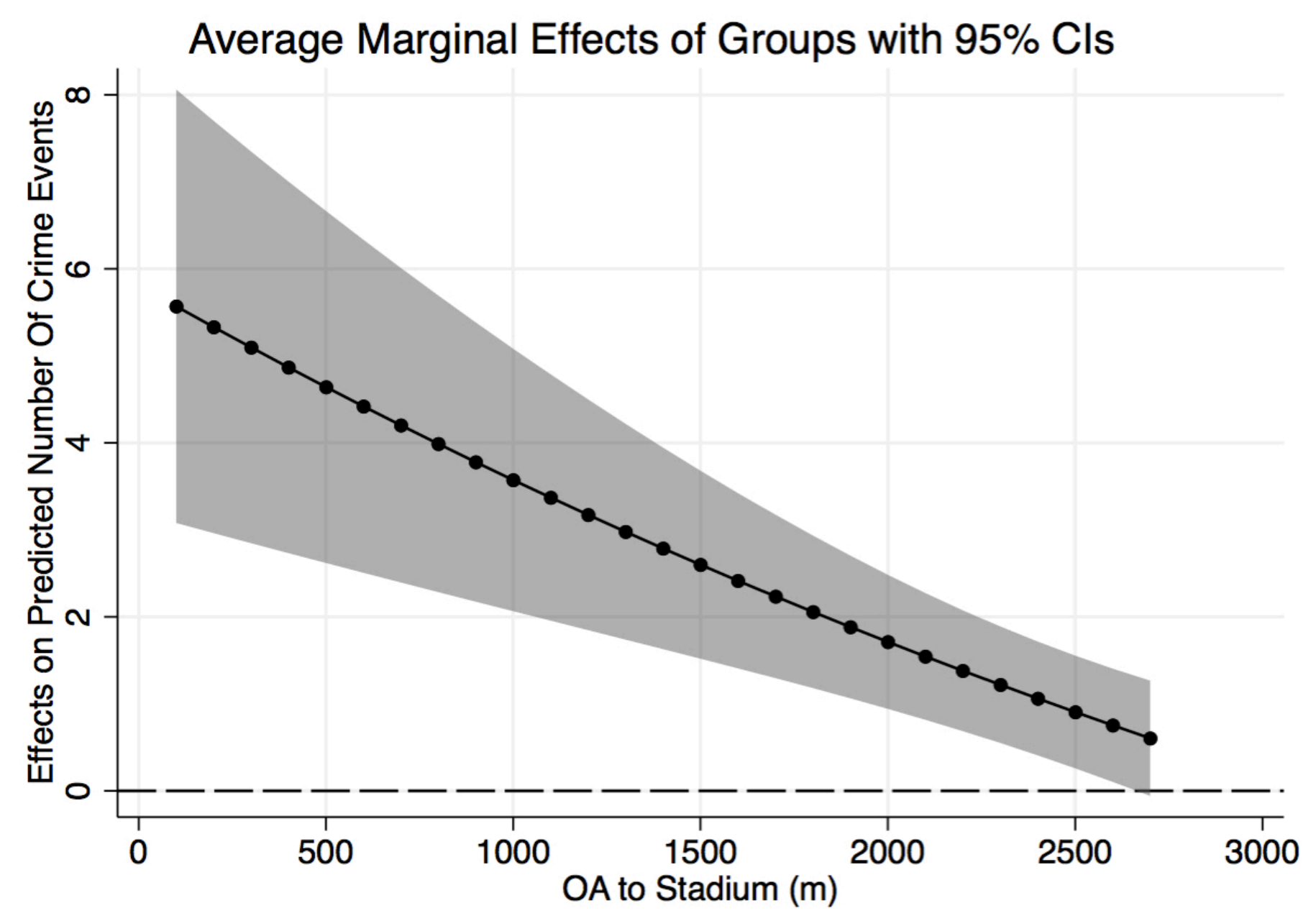


Figure 5. Average Marginal Effect of pub-to-stadium movement potential on crime event counts in an OA for match days.

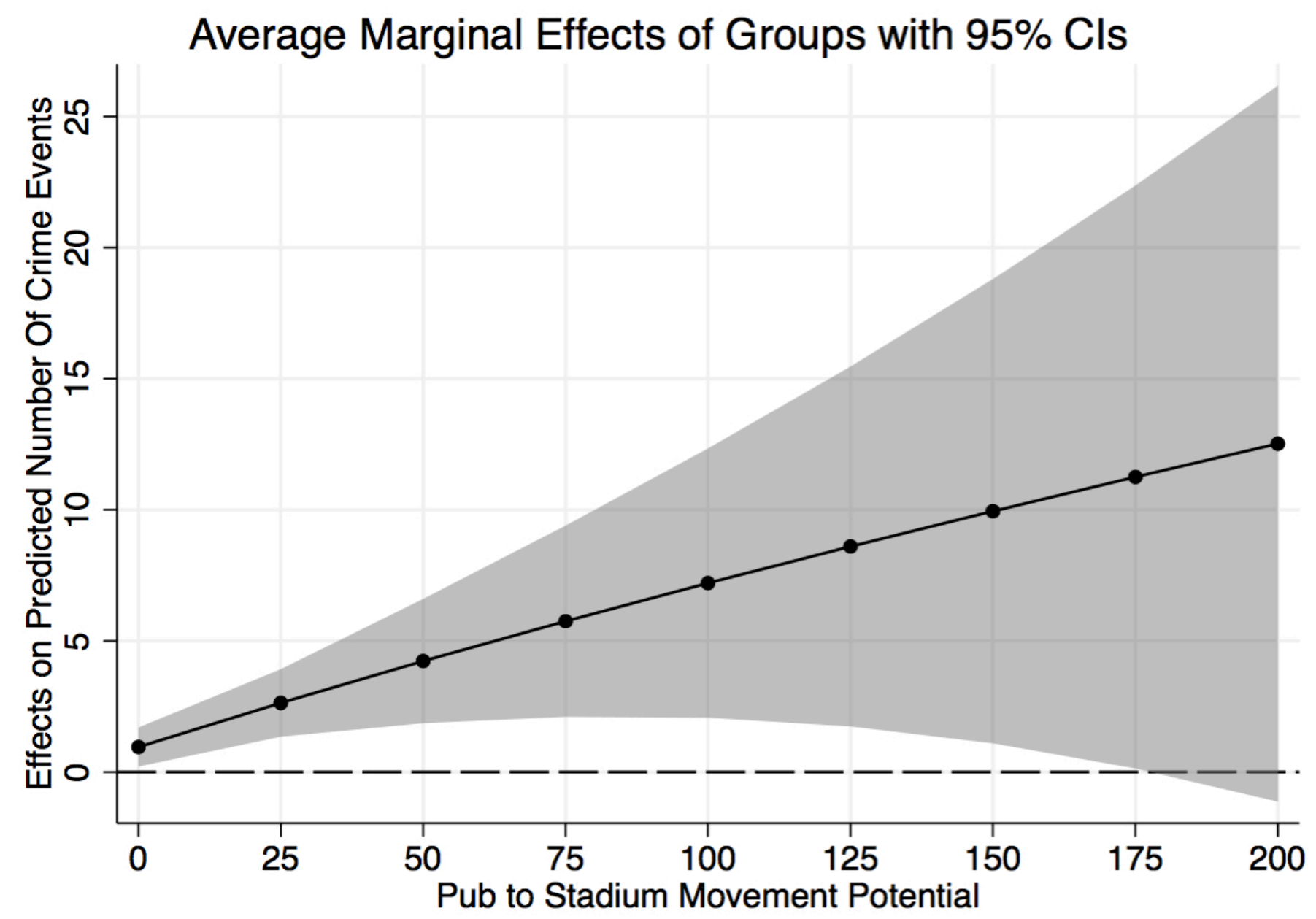


Figure 6. Average Marginal Effect of fast-food restaurant-to-stadium movement potential on crime event counts in an OA for match days.

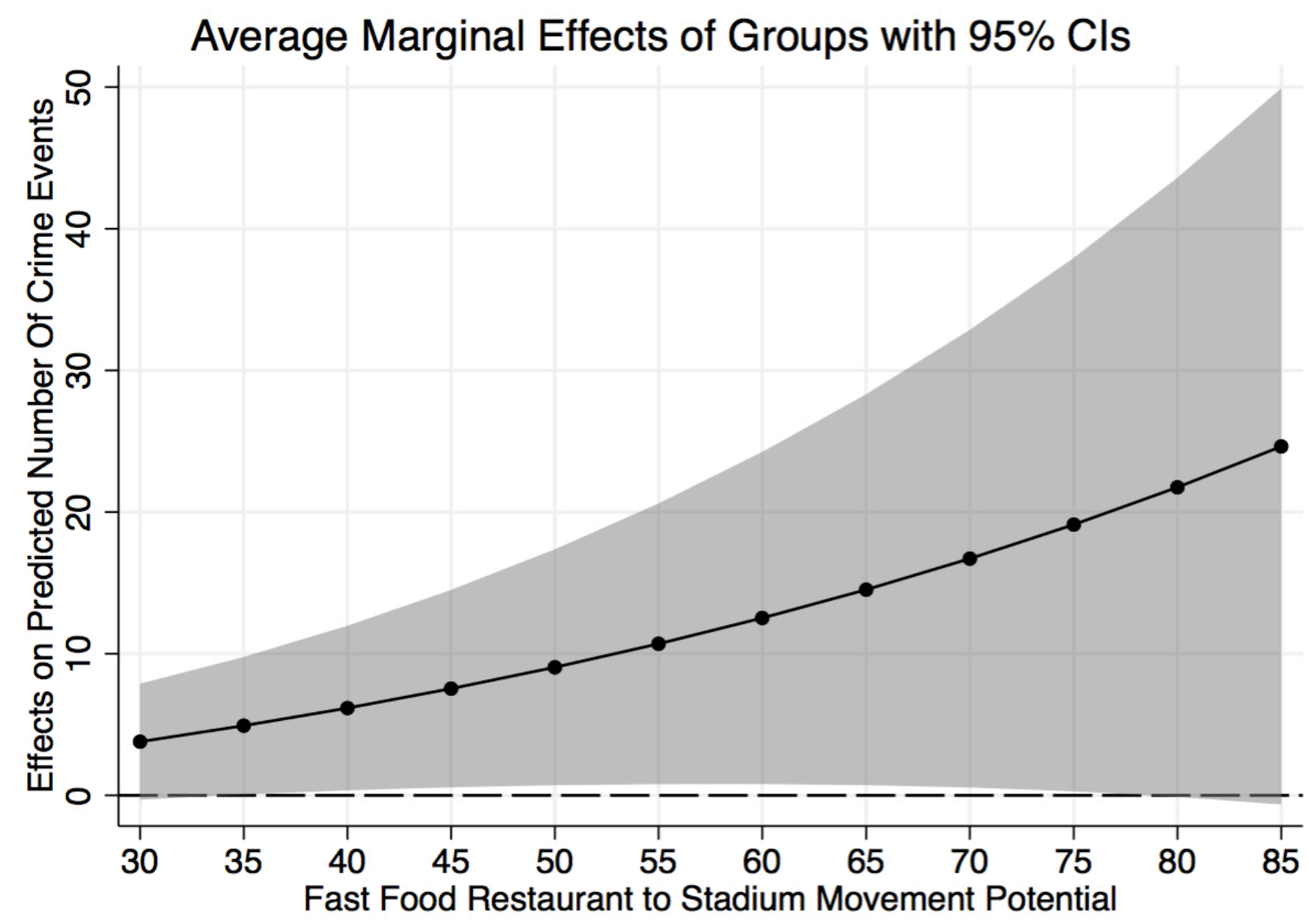


Appendix 1. Total crime counts for each stadium on match and comparison days, percentage of OAs that experienced one more crimes, and of variation in crime counts across the OAs (2005-2010).

\begin{tabular}{lcrrrrrr}
\hline Variable & $\begin{array}{c}\text { \%OAs with } \\
\text { Crime }\end{array}$ & $\begin{array}{c}\text { Total } \\
\text { Crime }\end{array}$ & Mean & SD & Min & Max & $\boldsymbol{N}$ \\
\hline Match & & & & & & & \\
$\quad$ Aston Villa & 99 & 2543 & 8.9 & 10.9 & 0 & 120 & 284 \\
$\quad$ Leeds United & 98 & 3251 & 15.0 & 24.7 & 0 & 332 & 216 \\
$\quad$ Sheffield United & 95 & 4470 & 12.0 & 36.7 & 0 & 419 & 370 \\
$\quad$ Sheffield Wednesday & 96 & 2163 & 7.4 & 9.0 & 0 & 79 & 289 \\
$\quad$ Wolverhampton & 97 & 3081 & 11.2 & 50.4 & 0 & 812 & 275 \\
$\quad$ Total & 97 & 15508 & 10.9 & 26.3 & 0 & 1762 & 1434 \\
\hline Comparison & & & & & & & \\
$\quad$ Aston Villa & 99 & 2094 & 7.3 & 8.4 & 0 & 112 & 284 \\
$\quad$ Leeds United & 99 & 2667 & 12.3 & 10.1 & 0 & 56 & 216 \\
$\quad$ Sheffield United & 96 & 4100 & 11.0 & 34.6 & 0 & 411 & 370 \\
$\quad$ Sheffield Wednesday & 95 & 1832 & 6.3 & 7.3 & 0 & 94 & 289 \\
$\quad$ Wolverhampton & 99 & 2901 & 10.5 & 45.3 & 0 & 730 & 275 \\
$\quad$ Total & 98 & 13594 & 9.5 & 21.1 & 0 & 1403 & 1434 \\
\hline
\end{tabular}

NOTE: SD = standard deviation 
Appendix 2. The percentage of OAs with facility of each type and variation in the number of facilities in each OA, variation in the exposure of an OA to facilities in contiguous OAs.

\begin{tabular}{|c|c|c|c|c|c|c|}
\hline Variable & $\begin{array}{c}\% \text { of OAs } \\
\text { with facility }\end{array}$ & Mean & SD & Min & Max & $N$ \\
\hline \multicolumn{7}{|l|}{ Pubs } \\
\hline Aston Villa & .04 & .05 & .29 & 0 & 3 & 17 \\
\hline Leeds United & .13 & .19 & .57 & 0 & 4 & 43 \\
\hline Sheffield United & .14 & .47 & 2.48 & 0 & 32 & 176 \\
\hline Sheffield Wednesday & .11 & .16 & .51 & 0 & 3 & 48 \\
\hline Wolverhampton & .12 & .24 & 1.68 & 0 & 26 & 68 \\
\hline Total & .11 & .24 & 1.50 & 0 & 32 & 352 \\
\hline \multicolumn{7}{|l|}{ Fast-food } \\
\hline Aston Villa & .11 & .19 & .62 & 0 & 4 & 54 \\
\hline Leeds United & .23 & .37 & .83 & 0 & 6 & 82 \\
\hline Sheffield United & .17 & .43 & 1.62 & 0 & 22 & 160 \\
\hline Sheffield Wednesday & .11 & .24 & .97 & 0 & 10 & 71 \\
\hline Wolverhampton & .11 & .30 & 2.12 & 0 & 34 & 83 \\
\hline Total & .15 & .31 & 1.38 & 0 & 34 & 450 \\
\hline \multicolumn{7}{|l|}{ Railway stations } \\
\hline Aston Villa & .050 & .02 & .16 & 0 & 2 & 2 \\
\hline Leeds United & .004 & .00 & .68 & 0 & 1 & 1 \\
\hline Sheffield United & .002 & .00 & .05 & 0 & 1 & 1 \\
\hline Sheffield Wednesday & .003 & .00 & .05 & 0 & 1 & 1 \\
\hline Wolverhampton & .003 & .00 & .60 & 0 & 1 & 1 \\
\hline Total & .012 & .01 & .15 & 0 & 2 & 6 \\
\hline \multicolumn{7}{|l|}{ Pubs "Spillover } \\
\hline Aston Villa & & .09 & .19 & 0 & 1.33 & 27.26 \\
\hline Leeds United & & .26 & .39 & 0 & 1.50 & 56.55 \\
\hline Sheffield United & & .59 & .64 & 0 & 13.33 & 220.52 \\
\hline Sheffield Wednesday & & .23 & .32 & 0 & 1.66 & 67.66 \\
\hline Wolverhampton & & .28 & .77 & 0 & 7.00 & 79.57 \\
\hline Total & & .31 & .94 & 0 & 13.33 & 451.57 \\
\hline \multicolumn{7}{|l|}{ Fast-food "Spillover" } \\
\hline Aston Villa & & .25 & .37 & 0 & 3.00 & 71.26 \\
\hline Leeds United & & .41 & .38 & 0 & 1.83 & 89.81 \\
\hline Sheffield United & & .55 & .87 & 0 & 7.66 & 204.96 \\
\hline Sheffield Wednesday & & .36 & .64 & 0 & 4.00 & 106.34 \\
\hline Wolverhampton & & .35 & .88 & 0 & 8.75 & 97.03 \\
\hline Total & & .39 & .69 & 0 & 8.75 & 569.42 \\
\hline \multicolumn{7}{|c|}{ Railway stations "Spillover" } \\
\hline Aston Villa & & .038 & .10 & 0 & .75 & 9.92 \\
\hline Leeds United & & .008 & .05 & 0 & .50 & 1.90 \\
\hline Sheffield United & & .003 & .02 & 0 & .33 & 1.46 \\
\hline Sheffield Wednesday & & .002 & .02 & 0 & .20 & .77 \\
\hline Wolverhampton & & .007 & .03 & 0 & .33 & 1.95 \\
\hline Total & & .010 & .06 & 0 & .75 & 15.55 \\
\hline
\end{tabular}

NOTE: $\mathrm{SD}=$ standard deviation 
Appendix 3. Descriptive statistics for the shortest network distance (SND) each OA was from the relevant stadium, estimates of movement potential for OAs in each of the five study areas (including the percentage of OAs with non-zero movement potential penetrated by a particular type of facility).

\begin{tabular}{|c|c|c|c|c|c|c|}
\hline Variable & $\begin{array}{c}\% \text { OAs }>0 \\
\text { movement }\end{array}$ & Mean & SD & Min & Max & $N$ \\
\hline \multicolumn{7}{|l|}{ OA to Stadium (m) } \\
\hline Aston Villa & & 2405.680 & 815.95 & 285 & 3923 & 284 \\
\hline Leeds United & & 2373.140 & 924.32 & 128 & 4274 & 216 \\
\hline Sheffield United & & 2324.450 & 788.39 & 225 & 3758 & 370 \\
\hline Sheffield Wednesday & & 2362.380 & 890.40 & 249 & 3070 & 289 \\
\hline Wolverhampton & & 2416.350 & 795.60 & 405 & 3828 & 275 \\
\hline Total & & 2376.550 & 838.06 & 128 & 4410 & 1434 \\
\hline \multicolumn{7}{|l|}{ Pub-to-stadium } \\
\hline Aston Villa & 27.0 & .990 & 2.99 & 0 & 27 & 284 \\
\hline Leeds United & 62.0 & 7.510 & 22.39 & 0 & 151 & 216 \\
\hline Sheffield United & 49.0 & 4.110 & 17.37 & 0 & 191 & 370 \\
\hline Sheffield Wednesday & 57.0 & 3.520 & 7.76 & 0 & 58 & 289 \\
\hline Wolverhampton & 49.0 & 1.900 & 7.19 & 0 & 71 & 275 \\
\hline Total & 48.0 & 3.460 & 13.45 & 0 & 191 & 1434 \\
\hline \multicolumn{7}{|l|}{ Fast-food-to-stadium } \\
\hline Aston Villa & 44.0 & 3.020 & 8.17 & 0 & 75 & 284 \\
\hline Leeds United & 65.0 & 7.470 & 17.00 & 0 & 143 & 216 \\
\hline Sheffield United & 54.0 & 4.740 & 14.79 & 0 & 174 & 370 \\
\hline Sheffield Wednesday & 44.0 & 3.240 & 9.02 & 0 & 73 & 289 \\
\hline Wolverhampton & 50.0 & 2.530 & 9.54 & 0 & 93 & 275 \\
\hline Total & 51.4 & 4.080 & 12.22 & 0 & 174 & 1434 \\
\hline \multicolumn{7}{|l|}{ Railway-to-stadium } \\
\hline Aston Villa & 16.0 & .235 & .70 & 0 & 6 & 284 \\
\hline Leeds United & 17.0 & .208 & .49 & 0 & 4 & 216 \\
\hline Sheffield United & 1.0 & .013 & .11 & 0 & 1 & 370 \\
\hline Sheffield Wednesday & 2.0 & .020 & .14 & 0 & 1 & 289 \\
\hline Wolverhampton & .3 & .003 & .06 & 0 & 1 & 275 \\
\hline Total & 7.2 & .086 & .39 & 0 & 6 & 1434 \\
\hline
\end{tabular}

NOTE: $\mathrm{SD}=$ standard deviation 
Appendix 4. Social Disorganization independent variables used to characterize the OAs for the five study areas.

\begin{tabular}{|c|c|c|c|c|c|}
\hline Variable & Mean & SD & Min & $\operatorname{Max}$ & $N$ \\
\hline \multicolumn{6}{|l|}{ Population density per $\mathrm{km}^{2}$} \\
\hline Aston Villa & 8131 & 6128 & 328 & 60645 & 284 \\
\hline Leeds United & 7350 & 5368 & 271 & 22758 & 216 \\
\hline Sheffield United & 8189 & 5568 & 537 & 51584 & 370 \\
\hline Sheffield Wednesday & 6699 & 3642 & 411 & 20761 & 289 \\
\hline Wolverhampton & 5750 & 3175 & 333 & 27521 & 275 \\
\hline Total & 7283 & 5018 & 271 & 60645 & 1434 \\
\hline \multicolumn{6}{|l|}{ Ethnic heterogeneity } \\
\hline Aston Villa & 5.22 & 1.53 & .38 & 7.45 & 284 \\
\hline Leeds United & 1.65 & 1.52 & .00 & 7.27 & 216 \\
\hline Sheffield United & 2.51 & 1.66 & .00 & 6.78 & 370 \\
\hline Sheffield Wednesday & 1.01 & 1.02 & .00 & 6.22 & 289 \\
\hline Wolverhampton & 4.35 & 1.73 & .62 & 7.23 & 275 \\
\hline Total & 2.97 & 2.18 & .00 & 7.45 & 1434 \\
\hline \multicolumn{6}{|l|}{ Population turnover } \\
\hline Aston Villa & 1.30 & .66 & .15 & 7.78 & 284 \\
\hline Leeds United & 1.44 & .79 & .26 & 6.94 & 216 \\
\hline Sheffield United & 2.48 & 1.73 & .23 & 9.62 & 370 \\
\hline Sheffield Wednesday & 1.28 & .83 & .30 & 7.05 & 289 \\
\hline Wolverhampton & 1.35 & .86 & .22 & 7.13 & 275 \\
\hline Total & 1.63 & 1.22 & .15 & 9.02 & 1434 \\
\hline \multicolumn{6}{|l|}{ IMD } \\
\hline Aston Villa & 1.86 & 1.35 & 1.86 & 6.96 & 284 \\
\hline Leeds United & 4.25 & 1.61 & .51 & 6.35 & 216 \\
\hline Sheffield United & 3.16 & 1.96 & .35 & 7.16 & 370 \\
\hline Sheffield Wednesday & 3.18 & 1.68 & .71 & 7.07 & 289 \\
\hline Wolverhampton & 3.80 & 1.71 & .74 & 7.68 & 275 \\
\hline Total & 3.87 & 1.87 & .35 & 7.68 & 1434 \\
\hline
\end{tabular}

NOTE: $\mathrm{SD}=$ standard deviation 
Appendix 5. Negative binomial regression of crime counts per OA around the five stadia (coefficients are Incidence Rate Ratios).

\begin{tabular}{|c|c|c|c|c|c|c|c|c|c|c|}
\hline \multirow[t]{2}{*}{ Variable } & \multicolumn{2}{|c|}{ Aston Villa } & \multicolumn{2}{|c|}{ Leeds } & \multicolumn{2}{|c|}{ Sheffield United } & \multicolumn{2}{|c|}{ Sheffield Wednesday } & \multicolumn{2}{|c|}{ Wolverhampton } \\
\hline & Match & Comparison & Match & Comparison & Match & Comparison & Match & Comparison & Match & Comparison \\
\hline \multicolumn{11}{|l|}{ Micro-level Risky Facility } \\
\hline Pubs & $1.70 * * *$ & $1.53 * * *$ & $1.39 * * *$ & $1.29 * *$ & $1.03^{*}$ & $1.06^{*}$ & $1.21 *$ & 1.08 & $1.16^{* * *}$ & $1.13 * * *$ \\
\hline Fast-food & $1.13 * * *$ & $1.30 * * *$ & 1.03 & 0.95 & $1.32 *$ & $1.15 * * *$ & $1.49 *$ & $1.12 *$ & $1.08 * * *$ & $1.47^{* *}$ \\
\hline Rail stations & 0.76 & 1.02 & 1.23 & 1.07 & 1.58 & 1.74 & 0.29 & 0.67 & 2.75 & 1.80 \\
\hline \multicolumn{11}{|c|}{ Micro-level Risky Facility "Spillover" } \\
\hline Pubs & $1.54 *$ & 1.06 & 1.22 & 1.14 & $1.01 * * *$ & $1.01^{*}$ & 1.06 & 1.02 & $1.07^{*}$ & 1.08 \\
\hline Fast-food & 1.04 & 1.01 & 1.00 & 1.01 & 1.09 & $1.14 *$ & $1.23^{*}$ & 1.51 & $1.06^{* *}$ & $1.41 * * *$ \\
\hline Rail stations & 0.77 & 0.80 & 1.97 & 1.20 & 2.00 & 2.37 & 0.96 & 0.67 & $1.67 *$ & 1.13 \\
\hline Match day crime & 0.99 & 0.99 & 1.00 & 1.00 & $1.01 * * *$ & $1.01 * *$ & 1.00 & $1.02 *$ & $1.01 * * *$ & 0.99 \\
\hline \multicolumn{11}{|l|}{ Super-Facility } \\
\hline OA to stadium $(\mathrm{km})$ & $0.98^{*}$ & 1.01 & $0.91 *$ & 1.02 & $0.86^{*}$ & 0.92 & $0.81^{*}$ & 1.01 & $0.92 * *$ & 1.08 \\
\hline \multicolumn{11}{|l|}{ Movement Potential } \\
\hline Pub-to-stadium & $1.04 *$ & 1.01 & $1.01 * * *$ & 1.00 & $1.01 * * *$ & $0.88^{*}$ & $1.01^{*}$ & 1.01 & $1.02 * *$ & 0.99 \\
\hline Fast-food-to-stadium & 1.02 & 1.00 & $1.01 * * *$ & 1.00 & $1.24 *$ & 1.14 & $1.02 *$ & 1.01 & $1.24 * *$ & 0.97 \\
\hline Rail-to-stadium & $1.30^{*}$ & 0.99 & 1.07 & 1.04 & $1.07 * * *$ & $0.19^{* *}$ & 0.97 & 0.74 & - & - \\
\hline \multicolumn{11}{|l|}{ Controls } \\
\hline Population turnover & $1.18^{* *}$ & $1.17^{* *}$ & $1.16^{*}$ & $1.13^{*}$ & $1.14 * * *$ & $1.14 * * *$ & 1.11 & 1.08 & $1.18^{* *}$ & $1.20 * * *$ \\
\hline Ethnic heterogeneity & 1.01 & 1.00 & 0.96 & 0.99 & 1.00 & 0.95 & 0.98 & 1.00 & $1.06^{*}$ & $1.09^{* * *}$ \\
\hline IMD & $1.07 *$ & $1.09 *$ & $1.25 * * *$ & $1.26 * * *$ & $1.18 * * *$ & $1.14 * * *$ & $1.16^{* * *}$ & $1.17 * * *$ & $1.17 * * *$ & $1.17 * * *$ \\
\hline Res. Pop. Density & $0.99 *$ & $0.99 * *$ & $0.99 * * *$ & $0.99 * *$ & $0.99 * * *$ & $0.99 * * *$ & $0.99 * * *$ & $0.99 *$ & $0.99 * * *$ & $0.99^{* * *}$ \\
\hline \multicolumn{11}{|l|}{ Diagnostics } \\
\hline Vuong & $-5.36 * * *$ & $-4.21 * * *$ & $-4.85 * * *$ & $-5.54 * * *$ & $-4.74 * * *$ & $-5.53 * * *$ & $-4.70 * * *$ & $-4.65 * * *$ & $-3.99 * * *$ & $-3.85 * * *$ \\
\hline Max VIF & 4.69 & 4.69 & 2.07 & 2.07 & 9.82 & 9.82 & 2.67 & 2.67 & 7.05 & 7.05 \\
\hline Condition No. & 5.14 & 5.14 & 3.33 & 3.33 & 9.62 & 9.62 & 3.94 & 3.94 & 5.46 & 5.46 \\
\hline Moran’s I (Pearson) & $0.01 * *$ & $-0.01 *$ & $0.05 * * *$ & 0.02 & $0.02 * * *$ & $-0.01 *$ & $0.06 * * *$ & $-0.04 *$ & $0.03 * *$ & $0.04 *$ \\
\hline$N$ & \multicolumn{2}{|c|}{284} & \multicolumn{2}{|c|}{216} & \multicolumn{2}{|c|}{370} & \multicolumn{2}{|c|}{289} & \multicolumn{2}{|c|}{275} \\
\hline
\end{tabular}

NOTE: $* \mathrm{p}<0.05, * * \mathrm{p}<0.01, * * * \mathrm{p}<0.001$. 